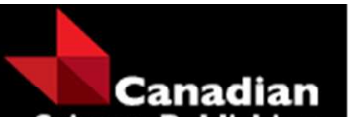

Science Publishing

Canadian Journal of Forest Research

Revue canadienne de recherche forestière

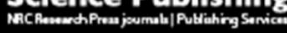

\title{
Effects of Plot Size, Stand Density and Scan Density on the Relationship between Airborne Laser Scanning Metrics and the Gini Coefficient of Tree Size Inequality
}

\begin{tabular}{|r|l|}
\hline Journal: & Canadian Journal of Forest Research \\
\hline Manuscript ID & cjfr-2017-0084.R2 \\
\hline Manuscript Type: & Article \\
\hline Date Submitted by the Author: & $27-$ Sep-2017 \\
\hline Complete List of Authors: & $\begin{array}{l}\text { Adnan, Syed; Ita-Suomen yliopisto Luonnontieteiden ja metsatieteiden } \\
\text { tiedekunta, Forest Sciences } \\
\text { Maltamo, Matti; University of Eastern Finland, School of Forest Sciences } \\
\text { Coomes, David; Department of Plant Sciences } \\
\text { Valbuena, Ruben; University of Cambridge. , Department of Plant Sciences }\end{array}$ \\
\hline $\begin{array}{r}\text { Keyword: } \\
\text { Is the invited manuscript for } \\
\text { consideration in a Special } \\
\text { Issue? : }\end{array}$ & $\begin{array}{l}\text { Sample Size Optimization, Forest Structure, LiDAR, Structural } \\
\text { Neterogeneity, Spatial Resolution Optimization }\end{array}$ \\
\hline
\end{tabular}




\section{Title:}

2 Effects of Plot Size, Stand Density and Scan Density on the Relationship between Airborne

3 Laser Scanning Metrics and the Gini Coefficient of Tree Size Inequality

\section{Authors:}

5 Syed Adnan *(1), Matti Maltamo (1), David Coomes (2), Rubén Valbuena (2)

\section{Affiliations:}




\section{Abstract}

29 The estimation of Gini Coefficient (GC) of tree sizes using airborne laser scanning (ALS) can 30 provide maps of forest structure across the landscape, which can support sustainable forest 31 management. A challenge arises in determining the optimal spatial resolution that maximizes 32 the stability and precision of $G C$ estimates, which in turn depends upon stand density or ALS 33 scan density. By subsampling different plot sizes within large field plots, we evaluated the 34 optimal spatial resolution by observing changes in $G C$ estimation and in its correlation with 35 ALS metrics. We found that plot size had greater effects than either stand density or ALS 36 scan density in the relationship between $G C$ and ALS metrics. Uncertainty in $G C$ estimates 37 fell as plot size increased. Correlation with ALS metrics showed convex curves with maxima at $250-450 \mathrm{~m}^{2}$, which thus was considered the optimal plot size / spatial resolution. By thinning the density of ALS point cloud, we deduced that at least 3 points $\cdot \mathrm{m}^{-2}$ are needed for reliable $G C$ estimates. Many nationwide ALS scan densities are sparser than this, which may

41 be unreliable for $G C$ estimation. Ours is a simple approach for evaluating the optimal spatial

42 resolution in remote sensing estimation of any forest attribute.

\section{$43 \quad$ Key words} structure; LiDAR 


\section{1. Introduction}

\section{1 1.1 The Gini Coefficient as an Indicator of Forest Structural Heterogeneity}

52 Forest structural characteristics are widely used in the development of sustainable 53 management plans designed to protect habitats while carrying out forestry operations (Upton 54 and Fingleton, 1985; Pommerening, 2002; Motz et al., 2010; Vihervaara et al., 2015; 55 Valbuena et al., 2016). Management can be designed to emulate natural dynamics (Oliver and Larson, 1990; Buongiorno et al., 1994; Lähde et al., 1999; Pukkala et al., 2016), by studying how silvicultural operations affects forest structure locally (Humphrey et al., 2000; Valbuena et al., 2013a; Robles et al., 2016).

Forest structure is often characterized by stem diameter distributions (O'Hara and Gersonde, 2004; McElhinny et al., 2005). If a single concise indicator of size inequality is desired, there are many available, including Shannon or Simpson indices (Neumann and Starlinger, 2001; Sterba and Ledermann, 2006; O'Hara et al., 2007; Lei et al., 2009) or variance-based metrics (Staudhammer and LeMay, 2001). Recent research has highlighted the effectiveness of the Gini coefficient (i.e. GC, Gini, 1921) for assessing the structural diversity (Lexerød and Eid, 2006a; O'hara et al. 2007; Duduman, 2009; Valbuena et al., 2012, 2013a). Originally developed for evaluating inequality in income distributions (e.g., Hvistendahl, 2014), GC has been applied to a variety of fields, such as healthcare (Asada, 2005) or land use (Zheng et al., 2013). In plant sciences, it has been employed to evaluate size inequality (Weiner and Solbrig, 1984). It has also been applied to forest ecosystems (Weiner and Thomas, 1986), to quantify structural diversity (Knox and Peet, 1989), analyse competition (Lundqvist, 1994;

71 Cordonnier and Kunstler, 2015), or successional stages (Valbuena et al., 2013a). Comparative studies indicate that $G C$ is the best index for characterizing diameter distributions, providing a logical ranking of different stand types (Lexerød and Eid, 2006a; Valbuena et al., 2012), so that forest may be stratified according to their structure (Bollandsås and Næsset, 2007). It can 
75 also be used to observe the effects of different management regimes (Bourdier et al., 2016;

76 Pukkala et al. 2016; Valbuena et al., 2016). For these reasons, estimation of GC is the focus

77 of this article.

78 When used in forest science, $G C$ evaluates size inequality of trees growing in a vicinity

79 (Weiner, 1990). For a patch of forest containing $n$ trees, within which the $i^{\text {th }}$ and $j^{\text {th }}$ tree have 80 basal areas of $g_{i}$ and $g_{j}$ respectively, $G C$ is calculated as (Glasser, 1962):

$$
G C=\frac{n}{(n-1)} \frac{\sum_{i=1}^{n} \sum_{j=1}^{n}\left|g_{i}-g_{j}\right|}{2 n^{2} \bar{g}}
$$

82 Therefore, $G C$ is a statistical measure of relative dispersion, which is equivalent to half of the 83 relative mean absolute difference (Valbuena et al, 2017: appendix A3), and it ranges between $840-1$, zero representing perfect equality and one being maximum inequality (Gini, 1921). 85 Hence GC describes the shape of tree-size distributions (Valbuena et al., 2016) and is 86 influenced by competitive interactions among trees (Cordonnier and Kunstler, 2015). 87 Valbuena et al. (2012) demonstrated that the $G C=0.5$ can be considered as a boundary between even-aged and uneven-aged stand structures. $G C$ values far below 0.5 indicate a

89 unimodal "normally distributed" size structure, which are commonly found in even-aged 90 stands that are self-thinning (e.g. Coomes and Allen, 2007). Values close to 0.5 indicate 91 irregular size distributions (Duduman, 2009), while values much greater than 0.5 represent 92 "reverse-J" stand structures (Valbuena et al., 2013a).

\subsection{Influence of Plot Size in Measurements of Forest Structure}

94 Sample plots used for measuring plant communities are usually rectangular or circular in 95 shape (Whittaker, 1972; Kent and Coker, 1992), with a wide range of possible plot sizes from 96 fine to coarse scales (Chytrý and Otýpková, 2003). As the effects of plot size decrease with 97 increasing size of a plot (David and Mishriky, 1968; Barbeito et al., 2009), an optimal size 
must be chosen compromising the acquisition of a field plot large enough to obtain a stable measure of forest structure, but no larger than necessary because of the costs involved (Otypková and Chytry, 2006). Structural diversity depends on the spatial resolution at which an index is evaluated (Lexerød and Eid, 2006b). Varying the scale of observation may therefore distort the information retrieved from an indicator (Chen and Crawford, 2012; Mauro et al, 2016). As plot size increases, GC estimates may be more reliable, but also fundamentally different stand conditions may aggregate (Coomes and Allen, 2007). Therefore, interpretation of data analysed at different scales remains one of the most challenging tasks in spatial statistics (Gotway and Young, 2002), as shown in the context of agriculture (Smith, 1938), sociology (Hannan, 1971), and environmental sciences (Jelinski and $\mathrm{Wu}, 1996)$. Also, the spatial distribution of trees has a practical effect on plot size, since clustered patterns require larger plot sizes to obtain a same degree of confidence in estimates (Upton and Fingleton, 1985; Pommerening, 2002; Kallimanis et al., 2008; Motz et al., 2010).

Recently, Magnussen et al. (2016) suggested a method of upscaling to a common plot size to minimize scale effects in survey estimates, which achieved consistency among the quantiles and proportions of sampling distributions of forest attributes.

\subsection{Influence of ALS Scan Density in Measurements of Forest Structure}

Airborne laser scanning (ALS) is recognised as a highly effective tool for regional monitoring because it provides precise information about biophysical stand properties, (Gobakken et al., 2006; Gobakken and Næsset, 2008). The GC may be calculated as a descriptor of the distribution of ALS heights (Valbuena et al., 2017), or ALS metrics may be related to $G C$ of tree sizes (Valbuena et al., 2013b). The spatial resolution of ALS data used in area-based methods has an effect on estimated values (Mascaro et al., 2011). In the context of remote sensing-assisted forest estimations, spatial resolution refers not only to the size of field plots but also to the size of pixels at which auxiliary variables are computed (Gobakken 
123 and Næsset, 2008; Ruiz et al., 2014; Valbuena et al., 2016). In ALS-assisted estimations of

$124 G C$ of tree size inequality, there is a lack of knowledge on the effects of varying plot size and 125 spatial resolution.

126 Scan density is one of the most important aspects of ALS datasets that affects both processing 127 and costs (Balsa-Barreiro and Lerma, 2014; Kandare et al., 2016). The importance of 128 optimizing ALS point density lays in its trade-offs against ALS swath width, and hence costs 129 (Baltsavias, 1999). Liu et al. (2007) observed that density reduction influenced the accuracy 130 of digital terrain models (DTM) due to the presence of empty space intervals between points. 131 A reduction in DTM accuracy may affect the calculation of metrics describing ALS height 132 (Ruiz et al., 2014; Singh et al., 2015), although it would be unlikely to affect metrics 133 describing their dispersion, such as GC. Gobakken and Næsset (2008) assessed the effect of 134 point density on biophysical stand properties, finding that maximum height was the least 135 affected metric and suggesting to avoid metrics most affected by point density. No previous 136 studies have yet determined how stand density and ALS scan densities affects GC estimates 137 from ALS.

\subsection{Objectives}

139 The aim of the study is to evaluate the effects of plot size and ALS scan density on field and 140 ALS-derived estimates of $G C$ in the boreal forests of Finland. We developed a simple method 141 for selecting the optimal plot size for determining the $G C$ of tree size inequality from field 142 data, and for predicting $G C$ reliably using ALS metrics as auxiliary variables. 
145 The study was carried out in a typical boreal managed forest located in Eastern Finland (62 $14631^{\prime} \mathrm{N}, 30^{\circ} 10^{\prime} \mathrm{E}$ ). Scots Pine (Pinus sylvestris L.) is the dominant species which represents $14773 \%$ of the total wood volume, while Norway spruce (Picea abies Karst.) represents 16\%, 148 and deciduous species $11 \%$ of the total wood volume (Valbuena et al., 2014). The main 149 properties of the field data such as stand density $(N)$, basal area $(G)$ and quadratic mean 150 diameter $(Q M D)$ are shown in Table 1. The field data were collected in May-June 2010 and 151 consisted of 79 squared plots (henceforth "original field plots") of various dimensions $152(20 \times 20,25 \times 25$ or $30 \times 30 \mathrm{~m}$, the smaller ones being in denser stands). With the intention of representing the contrast between highly homogeneous even-aged areas and more heterogeneous forest structures (Valbuena et al. 2016), forest stands were determined using stratified random sampling, whereas plot locations were purposively selected. After choosing the sampled stands, plots were located within the stands at a representative location. The reason for doing this was to avoid plot locations at stand borders and the high cost and measuring effort required to record the location of all individual stems within the plot. The absolute positions of every individual tree with $d b h>4 \mathrm{~cm}$ and tree top height taller than $4 \mathrm{~m}$ were mapped using an approach combining ALS and field surveying methods suggested by Korpela et al. (2007). Before the field measurement, a map of individual tree positions was generated from high density ALS data (see below) using an individual tree detection (ITD) method (Packalen et al., 2013). Actual positions of trees defined by their longitude/latitude coordinates $\left(X_{\text {actual }}, Y_{\text {actual }}\right)$ were verified in the field, while the location of trees not detected by the ITD method were measured relative to the ITD-derived ones (distances and bearings) and least-square adjusted (Korpela et al., 2007). 
169 Preliminary tasks for the simulation included transformations into relative coordinates, the 170 correction of edge effects and a sensitivity analysis to determine the number of simulations 171 needed. Then, within each original field plot we simulated circular plots at random positions.

172 Circular plots were chosen on the assumption that tree competition is the same in all spatial 173 directions. The radius of these circular simulated plots was increased in 1-m intervals, 174 generating concentric circles up to 15 m-radius. Since the position of individual trees were 175 available from the original field data, we could extract the trees located within each circular 176 simulated plots, computing an estimation of $G C$ based on tree $d b h$. Likewise, the position of 177 individual ALS returns located within each simulated circular plots could be extracted, using them to compute ALS metrics commonly employed in area-based estimation methods.

\subsubsection{Transformation to Relative Distances and Edge Correction}

Transformation of absolute tree coordinates into relative coordinates requires procedures of plot rotation and translation (Matos, 2014). Since in the case of our study the edges of original field plots were coincident with the UTM grid, there was no need to carry out plot rotations. In plot translation absolute coordinates of original field plots were modified into relative distances, by assigning the origin of axes $(0,0)$ to the south-western corner of the original field plot. Absolute coordinates of south-western corner $\left(X_{\text {corner }}, Y_{\text {corner }}\right)$ were subtracted from the absolute coordinates of each tree $\left(X_{a b s}, Y_{a b s}\right)$ to get their relative coordinates $\left(X_{\text {rel }}, Y_{\text {rel }}\right)$.

Moreover, Pommerening and Stoyan (2006) showed that edge effects play an important role in spatial statistics. Because the immediate neighbour trees outside the boundary of the original field plots were not measured, ignoring them would result in biased statistical 192 estimations. Thus, indices based on tree positions require an edge correction method to 
193 reduce this bias. We chose a periodic boundary edge correction method (Diggle, 2003), since 194 Pommerening and Stoyan, (2006) found it to be superior to other alternatives. This method 195 consisted of replicating the same spatial pattern measured in the field around the original 196 field plot (Fig. 1). Concentric circular simulated plots randomly positioned at the edge of the 197 original field plots therefore also included the trees positioned out of the boundaries of the 198 original field plots.

***approximate position of Figure $1 * * * *$

\subsubsection{Plot Simulation and Sensitivity Analysis}

A pilot sensitivity analysis was done with the intention to identify the minimum number of simulations within an original field plot which can guaranteed a stable and robust outcome for the simulation. We selected the original field plot with highest $G C$, hence likely the one most sensible to changes among different simulations, and repeated the analysis for 10,100 , 500, 700, 1000, 1500 and 2000 simulations. A position $\left(X_{\text {sim }}, Y_{\text {sim }}\right)$ was randomly simulated within the original field plot, and GC was calculated for each circular simulated plot (see below) and for each plot radius $(\mathrm{s} ; \mathrm{m})$ (1-m intervals from 1 to $15 \mathrm{~m})$ (Fig. 1). As explained below, the standard error of the mean (SEM) of values obtained for $G C$ at each radius were considered in order to fix the minimum number of simulations at which no considerable improvement was observed by adding further replications. After setting the necessary number of simulations to a fixed number $k$ based on the pilot sensitivity analysis,

212 the whole procedure was repeated for the remaining 78 original field plots. Relative and absolute positions of all simulations were recorded so that they could later be used for extracting their corresponding ALS returns as well.

\subsection{Gini Coefficient Estimation}


216 The target was to calculate sample estimations of the $G C$ describing the size inequality of the 217 tree community represented at each original field plot. Its estimation (Eq. 1) was repeated for 218 every concentric circular simulated plot of radii $1-15 \mathrm{~m}$, and for all the simulated 219 positions $\left(X_{\text {sim }}, Y_{\text {sim }}\right)$. For this purpose, basal area $\left(\mathrm{g} ; \mathrm{m}^{2}\right)$ was calculated for each individual 220 stem. Differences in g were computed for each pair of trees within each circular simulated plot. $G C$ is the average of absolute differences relative to their mean ( $\overline{\mathrm{g}}$ ) (see detailed descriptions of GC calculation in Lexerød and Eid (2006a) and Valbuena et al. (2013b)). The reason of using g instead of $d b h$ was to increase the influence of larger trees (Solomon and Gove, 1999). The unbiased estimator by Glasser (1962) was employed because it is appropriate for an estimation based on a finite number of trees $n$ located within each circular simulated plot (Eq. 1). The mean $G C(\overline{G C})$ and its corresponding $S E M$ were computed for each radius (from 1 to $15 \mathrm{~m}$ ), and for each of the original field plots. SEM is a measure for the accuracy of those means, accounting for the variability between the samples, according to the number of simulations $k$ and their sample standard deviation $(S D)$. R statistical software (R Development Core Team, 2016) was used for all these calculations and statistical analyses.

We constructed a graph comparing $\overline{G C}$ results for increasing plot size $s$ for all original field plots. The GC value at circular simulated plots must necessarily approximate asymptotically to the value of $G C$ for the entire original field plot as the radius of circular simulated plots increases (Matos, 2014). For this reason, the value of $G C$ obtained by applying equation (1) to the original field plot was used as a reference $\left(G C_{r e f}\right)$. In order to make all the simulated $G C$

237 values directly comparable, we calculated absolute $G C$ differences $\left(G C_{\text {diff }}\right)$ by subtracting simulated $G C$ values from the $G C_{r e f}$ :

$$
\overline{G C}_{\text {diff }}=\left|G C_{\text {ref }}-\overline{G C}\right|
$$


240 This way, it was possible to analyse the difference of each simulated GC to its corresponding 241 asymptotic value, allowing to set a common criterion to evaluate all simulations based on the 242 stabilization of the estimated $G C$ value (see below).

\subsection{Airborne Laser Scanning Data and Metric Computation}

244 ALS data was acquired on June 26, 2009 using ATM Gemini sensor (Optech, Canada) from $245 \quad 600-700 \mathrm{~m}$ above ground level with a $26^{\circ}$ field of view. Scan swath was $320 \mathrm{~m}$ wide with a $24655 \%$ side overlap between the strips. A high resolution dataset with 11.9 pulses $\cdot \mathrm{m}^{-2} \mathrm{scan}$ 247 density was produced from a pulse rate of $125 \mathrm{kHz}$. Details about the processing of ALS data are described in Packalen et al. (2013). The last echoes were classified as ground and interpolated into a DTM (Axelsson, 2000). The spatial resolution of DTM was $0.5 \mathrm{~m}$ based on the scan density, and the height above ground of individual ALS returns was obtained by subtraction of the DTM height beneath each of them. Echoes lower than $0.1 \mathrm{~m}$ from ground

Individual ALS returns of each circular simulated plot based on its absolute coordinates $\left(X_{\text {sim }}, Y_{\text {sim }}\right)$ were clipped, and area-based ALS metrics were computed from their heights with the help of FUSION software (USDA Forest Service; McGaughey, 2015). ALS metrics are statistics and descriptors of the distribution of ALS heights observed within a given area, which are usually employed as auxiliary variables in ALS-assisted forest estimations (Table 2). Some of these metrics were common statistics as, for example, the mean (Mean) standard deviation (StdDev) or the skewness (Skew) of the distribution of heights above ground of ALS returns contained within each circular simulated plot. We also computed the percentiles of their distribution, such as the $25^{\text {th }}(P 25), 50^{\text {th }}(P 50)$ or $99^{\text {th }}(P 99)$. In addition, we calculated the so-called canopy cover metrics (McGaughey, 2015), such as the proportion of returns backscattered from $0.1 \mathrm{~m}$ above the ground (Cover). Another metric 
264 included in FUSION was the canopy relief ratio $(C R R)$, which is the difference between 265 mean and minimum ALS return heights divided by a difference between maximum and 266 minimum heights (Pike and Wilson, 1971).

***approximate position of Table $2 * * * *$

The effect of plot size in the relationship with $G C$ was studied separately for each of these

269 ALS metrics. For each radius, we gathered all the simulations carried out at all the original 270 field plots and calculated all the ALS metrics listed in Table 2. They were used to calculate 271 Pearson correlation coefficients $(r)$ using all the combinations of field GC against each ALS metric. Then, we observed separately for each ALS metric the evolution of $r$ when increasing the plot size $s$ of the circular simulated plots. Since we were only interested in the capacity of the ALS metrics to explain variability in $G C$, regardless of whether their relationship was direct or indirect, we considered the absolute value of the correlation coefficient $|r|$ in the optimization, as explained below.

\subsection{Basic Relationships}

The plot size and spatial resolution at which an ALS-assisted estimation is carried out relates intrinsically to the sample size used in all calculations. Sample size affects the relationship between predictor and response, and therefore the accuracy of ALS estimation of any forest attributes (Gotway and Young, 2002; Mascaro et al., 2010; Næsset et al., 2015; Magnussen et al., 2016; Valbuena et al., 2016). In this context, sample size refers both to the number of trees used to calculate a given forest attribute, $G C$ in this case, but also to the number of ALS returns involved in the computation of ALS metrics. The link between resolution and sample size is employed on the empirical densities of the datasets, i.e. stand density $\left(N\right.$; trees $\left.\cdot \mathrm{ha}^{-1}\right)$ or

286 ALS points density $\left(d\right.$; points $\left.\cdot \mathrm{m}^{-2}\right)$ (Gobakken and Næsset, 2008; Motz et al., 2010; Jakubowski et al., 2013). Therefore, the effects of plot size and spatial resolution of the ALS 
288

289

290

291

292

293

294

296

297

298

299

300

301

302

303

304

305

306

307

308

309

estimated forest attributes also depend on $N$ and $d$, and the combined effects of these two factors may explain why plot sizes suitable for field surveys may be found sub-optimal for ALS estimation (Næsset et al., 2015).

Hence, the relationship between the radius $s$ of a circular plot and the number of trees $(n)$ contained within is tied to the $N$ at the location of the plot.

$$
n=N \pi s^{2}
$$

This begs the question on whether the optimization method should search for an optimal plot radius $\left(s^{*} ; \mathrm{m}\right)$ or an optimal sample size $\left(n^{*}\right)$. In a forest environment of variable stand density $N$ (Table 1), does the relationship between GC and ALS metrics depends on the plot size used, or on the number of trees surveyed? In order to research whether it makes a difference, we repeated the same procedure for both $s^{*}$ and $n^{*}$ optimization. In other words, we tested the results of optimization according to either plot radius or number of trees. In any of the cases, the relationship in eq. (4) assures that the methodology can be replicated for either dense or sparse forests, since $s$ and $n$ can always be deduced from one another by an empirical $N$.

Likewise, a similar relationship holds between the size of that same circular plot and the number of ALS returns backscattered from it, according to a given ALS scan density $d$. In this context of estimation using auxiliary variables, the scale concerns both to the size of the field plots and the spatial resolution of the pixel at which ALS metrics are calculated. Therefore, the number of ALS points $(p)$ relates to the spatial resolution / plot size used $(s)$ according to $d$ :

$$
p=d \pi s^{2}
$$


310 As before, the relationship in eq. (5) assures that the methodology can be replicated for any 311 range of ALS scan densities, since $s$ and $p$ are trivially deducted from one another by an 312 empirical $d$. As an overall conclusion, a given optimal plot size $s^{*}$ necessarily implies 313 optimal sample sizes as well, both $n^{*}$ and $p^{*}$. Keeping these relationships in mind is key to 314 demonstrating the validity of the optimization method for replication elsewhere according to 315 the $N$ and $d$ which may occur at any other study cases, and therefore the method is equally valid for both dense and sparse forests and ALS surveys with low or high scan density.

\subsection{Plot Size Optimization}

To optimize the plot size which should be used for a reliable $G C$ estimation, and thereby also the optimal spatial resolution for an estimation of $G C$ from ALS datasets, we determined two criteria to be applied sequentially: (1) stabilization of $G C$ as estimator of the population value from the field information itself, and (2) maximizing the $G C$ variability explained by ALS metrics. Therefore, Criterion I considered the minimum plot radius at which the estimation of GC remained stable to further increases in plot size. Criterion II was set to optimize the ALSassisted estimation, by observing changes in the correlation between the field $G C$ and each ALS metric among the simulated plot radii.

Criterion I was implemented by observing the evolution of $\overline{G C}_{\text {diff }}$ for increasing radii at every original field plot. We set a maximum value of $\overline{G C}_{\text {diff }}=0.05$ at which it was considered that the estimation of $G C$ was stable and representative of the population, and, therefore, selected the minimum plot radius $s$ as the smallest meeting the first criterion for all the 79 original field plots.

Criterion II consisted in maximizing the explained variance in the $G C$ values when predicted from ALS metrics. To implement this criterion we combined all the GC/ALS metric pairs for 
333 all the simulations carried out at all the original field plots, and grouped them according to 334 the different simulated radii. The optimal radius was set to be that one showing the maximum $335|r|$ value for a given metric. To make an overall decision, we put the focus on those metrics 336 showing higher correlations, and decided a range of optimal sizes accordingly (since the 337 empirical maximum may differ for different ALS metrics). As a summary, the final optimal 338 plot size $s^{*}$ for a given metrics was:

$$
s^{*}=\max |r| \mid \overline{G C}_{\text {diff }}<0.05
$$

\subsection{Sample Size Optimization}

341 For sample size optimization, seeking to deduct what is the minimum number of trees needed 342 to obtain a reliable $G C$ estimation, and the optimum for its ALS prediction, we applied the 343 same two sequential criteria employed for plot size optimization (section 2.6). Therefore, the 344 simulations were similar as before, but they increased the size of simulated circular plots 345 according to the resulting number of trees $n$ instead of plot radii. Thus, for implementing 346 Criterion I, the evolution of $\overline{G C}_{\text {diff }}$ was observed for increasing number of trees $n$, also 347 setting a maximum value of $\overline{G C}_{d i f f}=0.05$. As before, we selected the minimum $n$ as the smallest meeting Criterion I for all 79 original field plots. Criterion II also consisted in maximizing the absolute correlation between the $G C$ values and each of the ALS metrics. 350 New values of $|r|$ were obtained for increasing values of $n$, and the final optimal sample size 351

$$
n^{*}=\max |r| \mid \overline{G C}_{\text {diff }}<0.05
$$

353 Finally, we compared which alternative, eq. (6) or (7), would be more convenient for a 354 practical plot size optimization, discussing the results obtained by either method. 
355

356

357

358

359

360

361

362

363

364

365

366

367

368

369

370

371

372

373

374

375

376

377

378

\subsection{Reduction of ALS Point Density}

Once deduced an optimal spatial resolution $s^{*}$, we also investigated the effects of varying ALS scan density $d$. The original point density was reduced to $0.5,0.75,1,3,5,7.5$, and 10 points $\cdot \mathrm{m}^{-2}$. A common option to reduce point density is by moving a $1 \mathrm{~m}$ window and selecting random points from the point cloud to reach the desired point density (e.g., Magnussen et al. 2010). We calculated a correct thinning factor for each desired point density $d$ (Ruiz et al., 2014), following the method detailed by Jakubowski et al. (2013) which incorporates routines included in LAStools (RapidLasso GmbH Inc.; Isenburg, 2016). New ALS metrics over each of the $k$ simulated circular plot positions and their correlations against the $G C$ values obtained from the field information were calculated, and the entire procedure was repeated for all the reduced densities. In a similar manner as it was done for $s$ and $n$, the effects of varying ALS scan density were studied by observing the changes in $|r|$, i.e. the effects in the relationship between the $G C$ of tree size inequality and the ALS metrics with more explanatory capacity towards this given forest attribute.

\section{Results}

\subsection{Establishing the Number of Simulations}

Figure 2 shows the results of sensitivity analysis carried out to select the minimum number of simulations that would yield a robust estimation of $G C$ for increasing simulated plot radii. As expected, the $G C$ value estimated from few simulations fluctuated considerably, and this fluctuation decreased as the number of simulations increased (Fig. 2a). The expected general trend toward the asymptotic value obtained by the entire population $\left(G C_{r e f}\right)$ was generally observed in Fig. 2a. Very little variation in $G C$ estimates were observed when the number of simulations increased from 700. Similarly, the SEM decreased as the number of simulations increased (Fig. 2b), remaining virtually unchanged from 700 to 2000 simulations. 
379 Consequently, we decided to carry out the analysis using $k=700$ simulations of 15

380 concentric circular simulated plots located within each 79 original field plots.

\subsection{Plot Size Optimization}

383 Figure 3a shows the resulting $\overline{G C}_{\text {diff }}$ for each of the 79 original plots, and Table $\mathbf{3}$ is a summary of these results which was used for establishing Criterion I, which set the minimum plot size that would provide a reliable $G C$ estimation for the population. Circular simulated plots of small sizes provided $G C$ estimates that differed considerably from the population values as considered by $G C_{r e f}$. Nonetheless, once the estimation reached stabilization, an increase in the radius of a circular plot (and hence the sampling effort) would not necessarily imply a considerable change in the estimation of $G C$ (Fig. 3a). Our results showed that only few of the original field plots (probably very homogeneous stands) obtained stable $G C$ estimations from very small circular simulated plots (Table 3). On the other hand, for larger circular simulated plots the differences against the original field plots representing the population became negligible. We observed that stabilization of the $G C$ estimation started beyond of simulated plot radius $s=6 \mathrm{~m}$, from which all the original field plots fell within the $\overline{G C}_{\text {diff }}<0.05$ limit. We therefore established that the smallest plot size required for a reliable $G C$ estimation should be set at areas sizing around $113 \mathrm{~m}^{2}$.

***approximate position of Figure $3 * * * *$

***approximate position of Table $3 * * * *$

400 all ALS metrics included in FUSION. Results showed that changes in the relationship 401 between the field GC of tree sizes and metrics describing the distribution of ALS return 
402 followed some general trends and patterns. For this reason and for simplifying, we chose to 403 show only few ALS metrics in Fig. 4a, which we considered representatives of the general 404 trends observed. These ALS metrics were the described P25, P50, P99, Skew, StdDev, Cover 405 and $C R R$ (Table 2). Fig. 4a showed an erratic fluctuation for the values of $|r|$ obtained for 406 plot sizes smaller than a radius $s=5 \mathrm{~m}$, which was possibly caused by the instability 407 observed in the $G C$ estimation at smaller plot sizes (Fig. 3). For this reason, we shadowed this area in grey colour in Fig. 4, denoting that such small plot sizes were already dismissed under Criterion I. Once GC estimation reached stabilization, its correlation to ALS metrics often yielded a convex curve as plot size increased (Fig. 4a). Therefore, the optimal plot size was possible to determine via maximization of $|r|$. This tendency was more clearly marked for those ALS metrics showing higher values of $|r|$, i.e. more correlated to the $G C$ of tree sizes (eq. 2), such as Skew, Cover or CRR. For other ALS metrics less related to GC, like return height percentiles (P25, P50 or P99) or StdDev, this tendency was less marked (Fig. 4a). For the optimization of plot size, we selected those metrics showing highest correlation against $G C$, since in practice they would be those more involved in its estimation. Table 4 417 shows that the maximum $|r|$ for ALS metrics Skew, Cover or CRR ranged $s^{*}=9-12 \mathrm{~m}$ plot radius (the quality of histograms and scatterplots between variables involved can be checked in the Supplementary Material). It can be observed in Fig. 4a that beyond a circular 420 simulated plot of $12 \mathrm{~m}$ the correlation showed a decreasing trend for most ALS metrics. Also, 421 local maxima may be found for some ALS metrics for very small plot sizes, which is probably an artefact due to the above-mention instability in $G C$ estimation at very small plot sizes (Fig. 3). This proved the necessity of imposing Criterion I as a prior step to correlation maximization. As a conclusion, under the established combined Criteria I and II, we 425 determined that any plot radius $s<6 \mathrm{~m}\left(113 \mathrm{~m}^{2}\right.$ area) should be avoided (denoted by grey 426 colour in Fig. 4a), and the optimal plot size for an ALS-assisted estimation of $G C$ must be 
427 carried out using scales sizing $250-450 \mathrm{~m}^{2}$, which concerns to both the size of the field plot 428 and the pixel of the grid employed for ALS estimation.

***approximate position of Table $4 * * * *$

\subsection{Sample Size Optimization (Stand Density Effect)}

432 On the other hand, Figure $\mathbf{3 b}$ shows the evolution of $\overline{G C}_{\text {diff }}$ for increasing sample sizes 433 (number of trees $n$ ) at each of the 79 original field plots. It is worth mentioning the Figs. 3a and $\mathbf{3 b}$ relate to one another according to eq. (4). As a consequence, a similar tendency can be found for both of them. Table 3 expresses the number of trees that correspond on average to a given sample size. Therefore, the minimum value obtained for Criterion $I$ in plot size optimization, $s=6$, corresponds to stating that a minimum number of $n=15$ trees are required for a stable $G C$ estimation (shaded area in Fig. 4b). We nevertheless further postulated that this minimum number of trees may be dependent on the heterogeneity of the forest itself, being possibly larger in the presence of higher inequality of tree sizes. This 441 presumption was demonstrably true, as it can be observed in a scatterplot comparing the 442 minimum number of trees required for a stable $G C$ estimation at each of the 79 original plots 443 against their overall value of tree size inequality observed $\left(G C_{r e f}\right.$; Fig. 5). Such relationship 444 was not so straightforward if Criterion I was imposed using $s$ instead (results not shown), 445 which demonstrates the effect of varying forest stand density $N$. Hence, obtaining a stable $G C$ 446 estimation is more dependent of measuring a minimum number of trees than imposing a 447 given size for the field plot used. 
449 The case for Criterion II was different, as it can be deducted when observing the same ALS 450 metrics employed to optimize $s-P 25$, P50, P99, Skew, StdDev, Cover and CRR -, but trying 451 to optimize $n$ instead (Fig. 4b). Again, a similar tendency can be found since Figs.4a-b are 452 also related by eq. (4). Results were therefore very similar whether optimization was carried 453 out according to plot size (eq. 6) or sample size (eq. 7). The values of $|r|$ also followed a 454 convex curve when increasing the number of trees measured, and an optimal sample size $n^{*}$ 455 could be reliably determined via $|r|$ maximization. Our results showed that a number of trees 456 approximately ranging $n^{*}=30-60$ (Table 4) should be involved in the computation of $G C$, 457 in order to maximize the efficiency of its estimation using ALS. Since the value of $|r|$ 458 involves both the field GC and the ALS metrics, its changes are determined by both $N$ and $d$ 459 (eqs. 4-5), and both may cause a change in the correlation between the two variables.

3.4 Effect of Point Density on the Relationship of GC

461 According to the previous results, we set the optimal plot size to $s^{*}=9 \mathrm{~m}$ in order to further 462 analyse the possible effects due to varying scan density. Among all the ALS metrics (Table 2), we selected those same ones employed previously - P25, P50, P99, Skew, StdDev, Cover and $C R R$ - to allow direct comparison. Fig. 6 shows the evolution in $|r|$ for increasing ALS point density $d$. No considerable changes were observed in the correlation between the field $G C$ and the ALS metrics, which suggests that $d$ has no major effects on their relationship. 467 However, a decreasing trend in $|r|$ could generally be observed when point densities 468 decreased below $d<3$ points $\cdot \mathrm{m}^{-2}$ (Fig. 6). Overall, these results therefore suggest that the 469 relationship between GC and ALS metrics is mainly dependent on the plot size employed, 470 and rather independent of stand density and ALS scan density 
472

473

474

475

476

477

478

479

480

\section{Discussion}

In this study we evaluated the effects of plot size and sample size on the $G C$ of tree size inequality, and on its practical estimation using remote sensing methods based on ALS. Sample size refers to the number of individual elements (trees or ALS returns) included within a given sample area, which is therefore determined by the spatial resolution employed for evaluating a given forest attribute. We also analysed the effects of ALS scan density and, overall, we observed that plot size had greater effects on the relationship between $G C$ and ALS metrics than either of the other two criteria considered. The motivation for studying these effects is grounded on the fact that inappropriate plot sizes may provide unreliable estimates and lead to sub-optimal forest management decisions (Eid, 2000; Mauro et al., 2010). Valbuena et al. (2013a) pointed out that the estimation of $G C$ is affected by the area at which it is evaluated. Results in Fig. 3 illustrate how the $\overline{G C}_{\text {diff }}$ decreases when increasing the size of circular plots and, and hence their corresponding sample size. $\overline{G C}_{\text {diff }}$ values markedly dropped for smaller plot radii and sample sizes. This decrease smooths from bigger sizes, which indicates stabilization of the estimation (Criterion I). Fig. 2a also shows an example of this tendency to asymptotically approach the population value, which was also observed by George (2003), Barbeito et al. (2009), or Matos (2014). Based on Criterion I $\left(\overline{G C}_{\text {diff }}<0.05\right)$, the circular plot should be large enough $(s \geq 6 \mathrm{~m})$ to have minimum sample size of $n \geq 15$ trees (Fig. 3). Although the minimum plot size also depends on the stand density of an area, eq. (4) can be used to adjust the method to any forest areas, whether sparsely or densely forested. This conclusion may therefore be partly extended to other forest types, as it can be for example deduced (via eq. 4) that minimum radius of $s \geq 12 \mathrm{~m}$ would be needed in sparsely forested area of only $300 \mathrm{stems} \cdot \mathrm{ha}^{-1}$ (Lombardi et al., 2015). Eq. (4) therefore brings generality to the method, since plot sizes may hence be tailored to forest areas of differing stand densities. 
497 In this article we also postulated that maximizing the explained variability between the $G C$ 498 estimated from the field and ALS metrics could be a valid criterion to optimize the reliability 499 of ALS-assisted estimations of GC (Criterion II). Results in Fig. 4a showed that our 500 presumption was correct, since the $|r|$ values between $G C$ and most ALS metrics, especially 501 the most correlated ones, followed a convex curve with a maximum that could be searched to 502 reach an optimal plot size / spatial resolution for the estimation. On the other hand, once the 503 GC reached some stabilization, the correlation between them remains largely unchanged. 504 Therefore, a lower plot size limit is to be imposed to avoid local minima that could appear as 505 an artefact of the unstable estimation of $G C$ at low sample sizes. We shaded this area in grey 506 colour in Fig. 4 (a, b), denoting the area that was already dismissed as a result of Criterion I 507 (Fig. 3; George, 2003). In larger plots the sample size was more representative of the total average number of trees $\left(N \cong 1300\right.$ stems $\cdot \mathrm{ha}^{-1}$; Table 2$)$. According to these results, therefore, most forest datasets commonly acquired in operational inventories would be acceptable for an ALS-assisted estimation of the $G C$ of tree sizes. Lombardi et al. (2015) deduced a larger optimal plot radius $s^{*}=13-15 \mathrm{~m}$ for other forest attributes, most likely due to lower $N$ in the forest areas considered. For studies dealing with differing plot sizes, one 517 possibility could be to upscale $G C$ to a common plot size (Kent and Coker, 1992; Magnussen 518 et al., 2016).

519 Some of the reflexions raised in this article affect all other types of forest attributes and 520 remotely sensed auxiliary variables that may be used in forest estimations (Jelinski and $\mathrm{Wu}$, 521 1996). However, different forest attributes are differently affected by varying plot sizes 
522 (Chytrý and Otýpková, 2003). Some forest variables such as stand density or biomass would 523 show an averaging effect as plot size increases (Jelinski and Wu, 1996; Gotway and Young, 524 2002; Ruiz et al., 2014), which in turn derives in improved model efficiency when using 525 larger scales in remote sensing estimations (Næsset et al., 2015; Mauro et al., 2016). But 526 there is a trade-off between model accuracy and spatial resolution, and root mean squared 527 errors increase from $10-15 \%$ for $1000-4000 \mathrm{~m}^{2}$ to $20-25 \%$ for $200-250 \mathrm{~m}^{2}$ (Næsset, 2002 , 528 2004, 2007). However, this averaging effect is not applicable to forest attributes describing 529 structural diversity and heterogeneity (Coomes and Allen, 2007). In fact, many variables necessarily augment when the plot size increases, for instance species richness and diversity (e.g., Humphrey et al. 2000; Otypková and Chytry, 2006; Kallimanis et al., 2008; Fibich et al., 2016) as traditionally assessed through rarefaction (Kent and Coker, 1992). A similar effect can be observed in other measures of forest heterogeneity (Barbeito et al., 2009; Motz et al., 2010; McRoberts et al., 2012), and thus in the GC (Valbuena et al., 2013a, Matos, 2014), since increasing the size of a plot increases the probability of finding an additional differently-sized tree (Chen and Crawford, 2012; Valbuena et al., 2012). This is why estimated GC values in Fig. 3 asymptotically approach the value of the larger original field plot (George, 2003; Matos, 2014), which is never exceeded. Imposing a criterion defining which of the plausible plot sizes should be used is therefore not a trivial question to tackle. 540 Matos (2014) employed a number of different criteria based on the field information only stabilization of the estimate, stabilization of certainty of the estimate and convergence with $G C_{r e f}-$, none of them resulting fully satisfactory and definitive as they all ultimately rely on a subjective assumption (Cressie, 1993). For this reason, in this article we approached the 544 question of plot size from the viewpoint of its practical estimation using ALS remote sensing. 545 The convex curves obtained in Fig. 4a proved this approach to be highly beneficial, since maximization of correlation $|r|$ between $G C$ values and selected ALS predictors provides 
547 with a more objective method for determining the optimal plot size for the assessment of $G C$ 548 of tree size inequality. Still, due to the very high uncertainty observed in the estimation of $G C$ 549 when using very small plot sizes (Fig. 3b; Smith, 1938; Lombardi et al., 2015), we deducted 550 that a criterion avoiding great divergence with $G C_{r e f}$ may be imposed as a prior step to 551 maximization (Motz et al. (2010) referred to it as minimum grid spacing). Further research 552 could focus on modelling GC from ALS metrics and investigate how the interaction among 553 many ALS metrics in a same model may play a relevant role in the optimization of plot size 554 and spatial resolution.

555 The analyses carried out with reduced point densities revealed that lowering point density 556 barely affects the correlation between GC and ALS metrics, unless using a very sparse scan 557 density $d<3$ points $\cdot \mathrm{m}^{-2}$. Previous studies such as Maltamo et al. (2006), Ruiz et al. (2014) 558 or Singh et al. (2015) also indicate that reducing the point density is not affecting the 559 accuracy of volume prediction and demonstrate that the effects of varying scan densities can 560 be eluded in practical applications. It must be taken into account, however, that the DTM 561 used in this study was based on original point density, and the errors in DTM determination 562 at sparser densities (Liu et al., 2007; Ruiz et al., 2014) may induce to further uncertainty, 563 although this presumably has a lesser effect on those metrics most related to GC. 564 Furthermore, since ALS datasets from national programmes are currently surveying entire 565 countries at densities typically between $0.5-1$ points $\cdot \mathrm{m}^{-2}$ (Artuso et al., 2003), it must also be 566 pointed out the relevance of results in Fig. 6 which render most of these nation-wide ALS 567 datasets unsuitable for reliably estimating GC (Kandare et al. 2016). In line with results in 568 Valbuena et al. (2017), who postulated that the low densities incur in critical omission of 569 understorey development, our results demonstrate that indeed there is a need for increasing 570 point densities up to $d=3$ points $\cdot \mathrm{m}^{-2}$. This result is very concurrent with those obtained by 571 Ruiz et al. (2014) and Watt et al. (2014) for different forest attributes in different stand types, 
572 and therefore the case seems clear that ALS datasets obtained for forest applications should 573 reach this minimum density requirement.

\section{5. Conclusion}

575 In this study we studied how changing spatial resolution can affect the relationship between $576 G C$ and ALS metrics. We used three criteria for optimization: plot size, stand density and 577 ALS scan density. The effects of stand and scan densities are intimately interrelated to plot 578 size, since they together determine the sample size employed in calculations. Amongst those 579 three criteria, we found plot size to predominantly affect the relationship between $G C$ and 580 ALS metrics.

581 We observed that the estimation of $G C$ is strongly affected by the size of the forest plot 582 surveyed. Very small sample size and plot radii are more sensitive to $G C$ variations, 583 unrepresentative of the total population, producing unstable and unreliable $G C$ estimations. 584 The $G C$ estimation stabilizes as the size of plots and samples increases, as larger plots contain 585 a more appropriate number of observations (sample size) representing the population. We 586 determined that, in a boreal managed forest, a minimum number of 15 trees ought to be 587 measured for a reliable $G C$ estimation, regardless of the stand density present at each forest 588 stand.

589 We developed a method for plot size optimization based on a combination of two criteria: (1) 590 imposing a minimum of number of 15 trees measured, and (2) maximizing the absolute 591 correlation between field GC and ALS metrics. The plot level correlation between ALS 592 metrics and field GC showed a convex tendency for increasing plot sizes. Our results showed 593 that 9-12 m-radius plots produced the maximum correlation thus they are suitable for ALS- 
594 assisted $G C$ estimation. Basic relationships between plot size and sample size may be used to 595 accommodate the method to forested environments of varying stand densities.

596 With regards to the effects of ALS scan density, we observed that it can barely have any

597 effects unless lowered under 3 points $\mathrm{m}^{-2}$. This however may be relevant for the practical 598 application of low-density national datasets, and therefore we would recommend increasing 599 their scan densities with the intention to render nation-wide datasets useful for studying forest 600 heterogeneity.

\section{Acknowledgements}

602 This research was carried out in the framework of the project LORENZLIDAR: 603 Classification of Forest Structural Types with LiDAR remote sensing applied to study tree 604 size-density scaling theories, funded by a Marie S. Curie Individual Fellowship H202605 MSCA-IF-2014 (project 658180). Syed Adnan's PhD is funded by the National University of 606 Sciences and Technology (NUST), Pakistan under FDP 2014-15.

607

608

609

610

611

612

613

614

615

616

617

618

619

620

\section{References}

Asada, Y., 2005. Assessment of the health of Americans: the average health-related quality of life and its inequality across individuals and groups. Population Health Metrics 3, 7-7.

Artuso, R., Bovet, S., Streilein, A. 2003. Practical Methods for the Verification of Countrywide Terrain and Surface Models. ISPRS WG III/3 Workshop. 3-D reconstruction from airborne laser scanner and InSAR data. Dresden, Germany 8-10 October 2003. In: The International Archives of Photogrammetry, Remote Sensing and Spatial Information Sciences, Vol. XXXIV, part 3/WG13.

Axelsson, P., 2000. DEM generation from laser scanner data using adaptive TIN models. International Archives of Photogrammetry and Remote Sensing 33, 111-118.

Balsa-Barreiro, J., Lerma, J.L., 2014. Empirical study of variation in lidar point density over different land covers. Int. J. Remote Sens. 35, 3372-3383.

Baltsavias, E.P., 1999. Airborne laser scanning: basic relations and formulas. ISPRS Journal of photogrammetry and remote sensing 54, 199-214. 
621 Barbeito, I., Cañellas, I., Montes, F., 2009. Evaluating the behaviour of vertical structure 622 indices in Scots pine forests. Ann. For. Sci. 66, 710-710.

623 Bollandsås, O.M., Næsset, E., 2007. Estimating percentile-based diameter distributions in 624 uneven-sized Norway spruce stands using airborne laser scanner data. Scand. J. For. Res. 22, $625 \quad 33-47$.

626 Bourdier T., Cordonnier T., Kunstler G., Piedallu C., Lagarrigues G., Courbaud B. 2016. 627 Tree size inequality reduces forest productivity: an analysis combining inventory data for ten 628 european species and a light competition model. PLoS ONE 11(3), e0151852.

629 Buongiorno, J., Dahir, S., Lu, H., Lin, C., 1994. Tree Size Diversity and Economic Returns in 630 Uneven-Aged Forest Stands. For. Sci. 40, 83-103.

Chen, Z., Crawford, C.A.G., 2012. The role of geographic scale in testing the income inequality hypothesis as an explanation of health disparities. Soc. Sci. Med. 75, 1022-1031.

Chytrý, M., Otýpková, Z., 2003. Plot sizes used for phytosociological sampling of European 634

Coomes, D.A. and Allen, R.B., 2007. Mortality and tree-size distributions in natural mixedage forests. Journal of Ecology, 95(1), pp.27-40.

637 Cordonnier, T., and Kunstler, G. 2015. The Gini index brings asymmetric competition to 638 light. Perspectives in Plant Ecology, Evolution and Systematics, 17 (2), 107-115.

639 Cressie, N., 1993. Aggregation in Geostatistical Problems, in Soares, A. (Ed.), Geostatistics 640 Troia'92: Volume 1. Springer Netherlands, Dordrecht, pp. 25-36.

641 David, H.A., Mishriky, R.S., 1968. Order Statistics for Discrete Populations and for Grouped 642 Samples. Journal of the American Statistical Association 63, 1390-1398.

643 Diggle, P.J., 2003. Statistical Analysis of Spatial Point Patterns, 2nd ed. Arnold, London.

644 Duduman, G., 2009. An ecological approach for establishing the allowable cut in forests 645 where single tree selection system is applied. Editura Universităţii Suceava.[In Romanian] .

646 Eid, T., 2000. Use of uncertain inventory data in forestry scenario models and consequential 647 incorrect harvest decisions. Silva Fenn. 34, 89-100.

648 Fibich, P., Lepš, J., Novotný, V., Klimeš, P., Těšitel, J., Molem, K., Damas, K., Weiblen, 649 G.D., 2016. Spatial patterns of tree species distribution in New Guinea primary and 650 secondary lowland rain forest. Journal of Vegetation Science 27, 328-339.

651 George, D., 2003. The Small-Sample Bias of the Gini Coefficient: Results and Implications 652 for Empirical Research. Review of Economics and Statistics 85, 226-234.

653 Gini, C., 1921. Measurement of inequality of incomes. The Economic Journal 31, 124-126. 
654 Glasser, G.J., 1962. Variance formulas for the mean difference and coefficient of 655 concentration. Journal of the American Statistical Association 57, 648-654.

656 Gobakken, T., Næsset, E., Nelson, R., 2006. Developing regional forest inventory procedures 657 based on scanning LiDAR. Proceedings of the International Conference Silvilaser 2006, 658 Matsuyama, Japan. Japan Society of Forest Planning, Forestry and Forest Products Research 659 Institute and Ehime University. pp. 99-104.

660 Gobakken, T., Næsset, E., 2008. Assessing effects of laser point density, ground sampling 661 intensity, and field sample plot size on biophysical stand properties derived from airborne 662 laser scanner data. Canadian Journal of Forest Research 38, 1095-1109.

663 Gotway, C.A., Young, L.J., 2002. Combining incompatible spatial data. Journal of the 664 American Statistical Association 97, 632-648.

665 Hannan, M.T., 1971. Aggregation and Disaggregation in Sociology. Lexington Books.

666 Humphrey, J., Newton, A., Peace, A., Holden, E., 2000. The importance of conifer 667 plantations in northern Britain as a habitat for native fungi. Biol. Conserv. 96, 241-252.

668 Hvistendahl, M., 2014. While emerging economies boom, equality goes bust. Science, 344, $669 \quad 832-835$

670 Isenburg, M., 2016. "LAStools-efficient tools for LiDAR processing". (Version 160921, 671 academic). Retrieved from http://rapidlasso.com/LAStools.

672 Jakubowski, M.K., Guo, Q., Kelly, M., 2013. Tradeoffs between lidar pulse density and 673 forest measurement accuracy. Remote Sens. Environ. 130, 245-253.

674 Jelinski, D., Wu, J., 1996. The modifiable areal unit problem and implications for landscape 675 ecology. Landscape Ecol. 11, 129-140.

676 Kallimanis, A.S., Halley, J.M., Vokou, D. \& Sgardelis, S.P., 2008. The scale of analysis 677 determines the spatial pattern of woody species in the Mediterranean environment. Plant 678 Ecology 196: 143-151.

679 Kandare, K., Ørka, H.O., Chan, J.C.-W., Dalponte, M., 2016. Effects of forest structure and 680 airborne laser scanning point cloud density on 3D delineation of individual tree crowns. 681 European Journal of Remote Sensing, 49, pp. 337-359.

682 Kent, M., Coker, P., 1992. Vegetation description and analysis: a practical approach. 683 Chichester: Wiley.

684 Knox, R.G., Peet, R.K., Christensen, N.L., 1989. Population dynamics in loblolly pine stands: 685 changes in skewness and size inequality. Ecology 70, 1153-1167.

686 Korpela, I., Tuomola, T., Välimäki, E., 2007. Mapping forest plots: an efficient method 687 combining photogrammetry and field triangulation. Silva Fenn. 41. 
688 Lähde E., Laiho O., Norokorpi Y., 1999. Diversity-oriented silviculture in the boreal zone of 689 Europe. Forest Ecology and Management 118: 223-243.

690 Lei X., Wang W., Peng, C., 2009. Relationships between stand growth and structural 691 diversity in spruce-dominated forests in New Brunswick, Canada. Canadian Journal of Forest 692 Research 39, 1835-1847.

693 Lexerød, N., Eid, T., 2006a. An evaluation of different diameter diversity indices based on 694 criteria related to forest management planning. For. Ecol. Manage. 222, 17-28.

695 Lexerød, N., Eid, T., 2006b. Assessing suitability for selective cutting using a stand level 696 index. Forest Ecology and Management, 237(1-3), pp. 503-512.

697 Liu, X., Zhang, Z., Peterson, J., Chandra, S., 2007. The effect of LiDAR data density on 698 DEM accuracy. Proceedings of the International Congress on Modelling and Simulation 699 (MODSIM07) 2007, Modelling and Simulation Society of Australia and New Zealand Inc., 700 pp. 1363-1369.

Lombardi, F., Marchetti, M., Corona, P., Merlini, P., Chirici, G., Tognetti, R., Burrascano, S., Alivernini, A., Puletti, N., 2015. Quantifying the effect of sampling plot size on the 703 estimation of structural indicators in old-growth forest stands. For. Ecol. Manage. 346, 89-97.

704 Lundqvist, L., 1994. Growth and Competition in Partially Cut Sub-Alpine Norway Spruce 705 Forests in Northern Sweden. For. Ecol. Manage. 65, 115-122.

706 Magnussen, S., Mandallaz, D., Lanz, A., Ginzler, C., Næsset, E., Gobakken, T., 2016. Scale 707 effects in survey estimates of proportions and quantiles of per unit area attributes. For. Ecol. 708 Manage. 364, 122-129.

Maltamo, M., Eerikäinen, K., Packalén, P., Hyyppä, J., 2006. Estimation of stem volume 710 using laser scanning-based canopy height metrics. Forestry 79, 217-229.

Mascaro, J., Detto, M., Asner, G.P., Muller-Landau, H.C., 2011. Evaluating uncertainty in mapping forest carbon with airborne LiDAR. Remote Sens. Environ. 115, 3770-3774.

713 Matos, A., 2014. Effect of scale factor in estimation of Gini coefficient. Master's thesis.

714 University of Eastern Finland.

715 http://epublications.uef.fi/pub/urn_nbn_fi_uef-20140718/index_en.html

716 http://www.oppi.uef.fi/opk/video/europeanforestry/a_matos_seminar.mp4

717 (accessed August 2016)

Mauro, F., Valbuena, R., Manzanera, J., García-Abril, A., 2010. Influence of Global Navigation Satellite System errors in positioning inventory plots for tree-height distribution studies Canadian journal of forest research 41, 11-23. 
724 McElhinny, C., Gibbons, P., Brack, C., Bauhus, J., 2005. Forest and woodland stand 725 structural complexity: Its definition and measurement. For. Ecol. Manage. 218, 1-24.

726 McGaughey, R., 2015. FUSION/LDV: Software for LIDAR data analysis and visualization. 727 Version 3.50. Forest Service. Pacific Northwest Research Station. United States Department 728 of Agriculture. [Accessed December, 2015].

729 McRoberts, R.E., Winter, S., Chirici, G., LaPoint, E., 2012. Assessing Forest Naturalness. 730 For. Sci. 58, 294-309.

731 Motz, K., Sterba, H., Pommerening, A., 2010. Sampling measures of tree diversity. For. Ecol. 732 Manage. 260, 1985-1996.

733 Næsset, E., 2002. Predicting forest stand characteristics with airborne scanning laser using a 734 practical two-stage procedure and field data. Remote Sens. Environ. 80, 88-99.

735 Næsset, E., 2004. Accuracy of forest inventory using airborne laser scanning: evaluating the 736 first Nordic full-scale operational project. Scand. J. For. Res. 19, 554-557.

737 Næsset, E., 2007. Airborne laser scanning as a method in operational forest inventory: Status 738 of accuracy assessments accomplished in Scandinavia. Scand. J. For. Res. 22, 433-442.

739 Næsset, E., Bollandsås, O.M., Gobakken, T., Solberg, S., McRoberts, R.E., 2015. The effects 740 of field plot size on model-assisted estimation of aboveground biomass change using 741 multitemporal interferometric SAR and airborne laser scanning data. Remote Sens. Environ. $742168,252-264$.

743 Neumann, M., Starlinger, F., 2001. The significance of different indices for stand structure 744 and diversity in forests. For. Ecol. Manage. 145, 91-106.

745 O'Hara, K.L., Gersonde, R.F., 2004. Stocking control concepts in uneven-aged silviculture. 746 Forestry 77, 131-143.

747 O’Hara, K.L., Hasenauer, H., Kindermann, G., 2007. Sustainability in multi-aged stands: an 748 analysis of long-term plenter systems. Forestry 80, 163-181.

749 Oliver, C.D., Larson, B.C., 1990. Forest Stand Dynamics. McGraw-Hill, Inc.

750 Otypková, Z., Chytry, M., 2006. Effects of plot size on the ordination of vegetation samples. 751 Journal of Vegetation Science 17, 465-472.

752 Packalen, P., Vauhkonen, J., Kallio, E., Peuhkurinen, J., Pitkänen, J., Pippuri, I., Strunk, J., 753 Maltamo, M., 2013. Predicting the spatial pattern of trees by airborne laser scanning. Int. J. 754 Remote Sens. 34, 5154-5165.

755 Pike, R.J., Wilson, S.E., 1971. Elevation-relief ratio, hypsometric integral, and geomorphic 756 area-altitude analysis. Geological Society of America Bulletin 82, 1079-1084.

757 Pommerening, A., 2002. Approaches to quantifying forest structures. Forestry 75, 305-324. 
758 Pommerening, A., Stoyan, D., 2006. Edge-correction needs in estimating indices of spatial 759 forest structure. Canadian Journal of Forest Research 36, 1723-1739.

760 Pukkala, T., Laiho, O., Lähde, E., 2016. Continuous cover management reduces wind 761 damage. For. Ecol. Manage. 372, 120-127.

R Development Core Team, 2016. R: A language and environment for statistical computing. R Foundation for Statistical Computing, Vienna, Austria. ISBN 3-900051-07-0, URL http://www.R-project.org.

Robles, A., Rodríguez, M.A., Alvarez-Taboada, F. 2016. Characterization of wildland-urban interfaces using LiDAR data to estimate the risk of wildfire damage. Revista de Teledeteccion, 45: 57-69.

Ruiz, L.A., Hermosilla, T., Mauro, F., Godino, M. 2014. Analysis of the influence of plot size and LiDAR density on forest structure attribute estimates. Forests, 5 (5): 936-951

Singh, K.K., Chen, G., McCarter, J.B., Meentemeyer, R.K. 2015. Effects of LiDAR point density and landscape context on estimates of urban forest biomass. ISPRS Journal of Photogrammetry and Remote Sensing, 101: 310-322

Smith, H.F., 1938. An empirical law describing heterogeneity in the yields of agricultural crops. The Journal of Agricultural Science 28, 1-23.

Staudhammer, C.L., LeMay, V.M., 2001. Introduction and evaluation of possible indices of stand structural diversity. Canadian journal of forest research 31, 1105-1115.

Sterba, H., Ledermann, T., 2006. Inventory and modelling for forests in transition from evenaged to uneven-aged management. For. Ecol. Manage. 224, 278-285.

Upton, G., Fingleton, B., 1985. Spatial Data Analysis by Example. Volume 1: Point Pattern and Quantitative Data. John Wiley \& Sons Ltd.

Valbuena, R., Packalén, P., Martín-Fernández, S., Maltamo, M., 2012. Diversity and equitability ordering profiles applied to study forest structure. For. Ecol. Manage. 276, 185195.

Valbuena, R., Packalen, P., Mehtätalo, L., García-Abril, A., Maltamo, M., 2013a. Characterizing forest structural types and shelterwood dynamics from Lorenz-based indicators predicted by airborne laser scanning. Canadian Journal of Forest Research 43, 1063-1074.

Valbuena, R., Maltamo, M., Martín-Fernández, S., Packalen, P., pascual, C. and Nabuurs, G., 2013b. Patterns of covariance between airborne laser scanning metrics and Lorenz curve descriptors of tree size inequality. Canadian Journal of Remote Sensing, 39, pp. S18-S31.

Valbuena, R., Vauhkonen, J., Packalen, P., Pitkänen, J., Maltamo, M., 2014. Comparison of airborne laser scanning methods for estimating forest structure indicators based on Lorenz curves. ISPRS Journal of Photogrammetry and Remote Sensing 95, 23-33. 
794 Valbuena, R., Eerikainen, K., Packalen, P., Maltamo, M., 2016. Gini coefficient predictions 795 from airborne lidar remote sensing display the effect of management intensity on forest 796 structure. Ecol. Ind. 60, 574-585.

797 Valbuena, R., Maltamo, M., Mehtätalo, L., Packalen, P., 2017. Key structural features of 798 boreal forests may be detected directly using 1-moments from airborne lidar data. Remote 799 Sensing of Environment 194: 437-446.

800 Vihervaara P., Mononen L., Auvinen A.P., Virkkala R., Lü Y., Pippuri I., Packalen P., 801 Valbuena R., Valkama J., 2015. How to Integrate Remotely Sensed Data and Biodiversity for 802 Ecosystem Assessments at Landscape Scale. Landscape Ecology 30 (3): 501-516.

803 Watt, M.S., Meredith, A., Watt, P., Gunn, A., 2014. The influence of LiDAR pulse density on 804 the precision of inventory metrics in young unthinned Douglas-fir stands during initial and 805 subsequent LiDAR acquisitions. New Zealand Journal of Forestry Science, 44 (1), 9 p.

806 Weiner, J., 1990. Asymmetric competition in plant populations. Trends in Ecology \& 807 Evolution, 5(11), pp. 360-364.

808 Weiner, J., Solbrig, O.T., 1984. The meaning and measurement of size hierarchies in plant 809 populations. Oecologia 61, 334-336.

810 Weiner J., Thomas S., 1986. Size variability and competition in plant monocultures. Oikos 811 47: 211-222.

812 Whittaker, R.H., 1972. Evolution and measurement of species diversity. Taxon, 213-251.

813 Zheng, X., Xia, T., Yang, X., Yuan, T., Hu, Y., 2013. The Land Gini Coefficient and Its 814 Application for Land Use Structure Analysis in China. PLoS ONE 8, 1-10.

Table Titles

817 Table 1. Properties of the study area.

Table 2. Summary of ALS metrics computed with FUSION and used in this research 820 (McGaughey, 2015).

Table 3. For each radii, proportion of the total number of original field plots within the $\overline{G C}_{\text {diff }}<0.05$ limit (Criterion I), and average number of trees contained within those plots. 
825 Table 4. Maximum absolute correlation between field GC and ALS predictors (Criterion II). 826 See Table 2 for description of ALS metrics.

\section{Figure Captions}

830

Figure 1. Reproduction of tree positions (dots) within an original field plot (red rectangle) 832 surrounded by edge correction i.e. translation method (i.e. periodic boundary), and a sample 833 of 10 random realizations of simulated concentric circular plots with radii sizing 1-3 m (for simplicity). Axes show both absolute (above) and relative (below) coordinates (respectively $X_{a b s}, Y_{a b s}$ and $X_{r e l}, Y_{r e l}$ in Eq. 2).

Figure 2. Results of sensitivity analysis to select minimum numbers of simulations.

838 Evolution for increasing radii of (a) mean $\widehat{G C}$ values and (b) their standard errors for $k=$ 839 10-2000 simulations.

841 Figure 3. Criterion I. Asymptotic representation showing the evolution of $\overline{G C}_{d i f f}$ (at each of 842 the 79 original field plots) for increasing (a) plot sizes $s=1-15 \mathrm{~m}$ radius (corresponding area 843 also shown in upper axis) (b) and sample size $n=1-50$ number of trees (shortened to 844 enhance visualization). 
846 Figure 4. Criterion II. Absolute of correlation $|r|$ between GC values and selected ALS 847 predictors (see legend, and explanations of ALS metrics in Table 1 and section 2.4) for 848 increasing (a) plot size $s=1-15 \mathrm{~m}$ radius (corresponding area also shown in upper axis) (b) 849 and sample size $n=1-90$ number of trees.

850

851 Figure 5. Minimum number of trees (sample size) to reach $G C$ stabilisation in relation to the 852 reference $G C$ value obtained from the original field plot $\left(G C_{r e f}\right)$.

853

854 Figure 6. Changes due to varying ALS scan densities in the absolute of correlation $|r|$ 855 between $G C$ values and ALS predictors. See explanations of ALS metrics in Table 1 (section $8562.4)$.

857

858 Supplementary Materials

859 Supplementary Figure 1. Histograms showing the distribution of the response variable $860 \overline{G C}$ (vertical bars) - and the predictor variables - Skewness, Cover, CRR, P99, StdDev, P50 861 and $P 25$ (horizontal bars) -. The resulting scatterplots between each response-predictor pair 862 are also shown. For simplicity, only results for the optimal plot radius $s^{*}=9 \mathrm{~m}$ are shown. 
Table 1. Properties of the study area.

\begin{tabular}{lcccc}
\hline Parameter & Minimum & Mean & Maximum & SD \\
\hline$N\left(\mathrm{stems} \cdot \mathrm{ha}^{-1}\right)$ & 467 & 1298 & 3025 & 594 \\
$G\left(\mathrm{~m}^{2} \cdot \mathrm{ha}^{-1}\right)$ & 14 & 25 & 44 & 7 \\
$Q M D(\mathrm{~cm})$ & 10 & 17 & 29 & 4
\end{tabular}

$N$ : stand density; $G$ : basal area; $Q M D$ : quadratic mean diameter; SD: standard deviation. 
Table 2. Summary of ALS metrics computed with FUSION and used in this research (McGaughey, 2015).

\begin{tabular}{lll}
\hline Symbol & Description & Forest Characteristics \\
\hline P50 & Median (i.e. $50^{\text {th }}$ percentile $)$ & Average tree height \\
StdDev & Standard deviation & Variation in tree heights \\
Skew & Skewness & Tree dominance \\
$P 25$ & $1^{\text {st }}$ quartile (i.e. $25^{\text {th }}$ percentile) & Presence of understorey \\
$P 99$ & $99^{\text {th }}$ percentile & Dominant height \\
CRR & Canopy relief ratio $=($ Mean - Min $) /($ Max - Min $)$ & Vertical structure \\
Cover & Percentage of all returns above $2 \mathrm{~m}$ & Canopy cover \\
\hline
\end{tabular}


Table 3. For each radii, proportion of the total number of original field plots within the $\overline{G C}_{d i f f}<$ 0.05 limit (Criterion I), and average number of trees contained within those plots.

\begin{tabular}{ccc}
\hline $\begin{array}{c}\text { Plot } \\
\text { radius } \\
(\mathrm{m})\end{array}$ & $\begin{array}{c}\text { Ratio of original } \\
\text { field plots reaching } \\
\text { stabilization }(\%)\end{array}$ & $\begin{array}{c}\text { Average sample size } \\
\text { of trees based on } \\
\text { simulations }\end{array}$ \\
\hline 1 & 25.3 & 1.1 \\
2 & 41.1 & 2.0 \\
3 & 70.8 & 3.7 \\
4 & 94.9 & 6.5 \\
5 & 91.4 & 10.2 \\
6 & 100 & 14.6 \\
7 & 100 & 19.9 \\
8 & 100 & 26.1 \\
9 & 100 & 33.0 \\
10 & 100 & 40.7 \\
11 & 100 & 49.3 \\
12 & 100 & 58.7 \\
13 & 100 & 68.9 \\
14 & 100 & 79.9 \\
15 & 100 & 91.7 \\
\hline
\end{tabular}


Table 4. Maximum absolute correlation between field GC and ALS predictors (Criterion II). See Table 2 for description of ALS metrics.

\begin{tabular}{cccc}
\hline $\begin{array}{c}\text { ALS } \\
\text { metric }\end{array}$ & $\begin{array}{c}\text { Maximum } \\
\text { correlation } \\
\max |r|\end{array}$ & $\begin{array}{c}\text { Optimal } \\
\text { plot radius } \\
\left(s^{*} ; \mathrm{m}\right)\end{array}$ & $\begin{array}{c}\text { Optimal } \\
\text { number of trees } \\
\left(n^{*} ; \mathrm{m}\right)\end{array}$ \\
\hline Skew & 0.58 & 10 & 41 \\
Cover & 0.45 & 12 & 59 \\
CRR & 0.42 & 9 & 33 \\
\hline
\end{tabular}




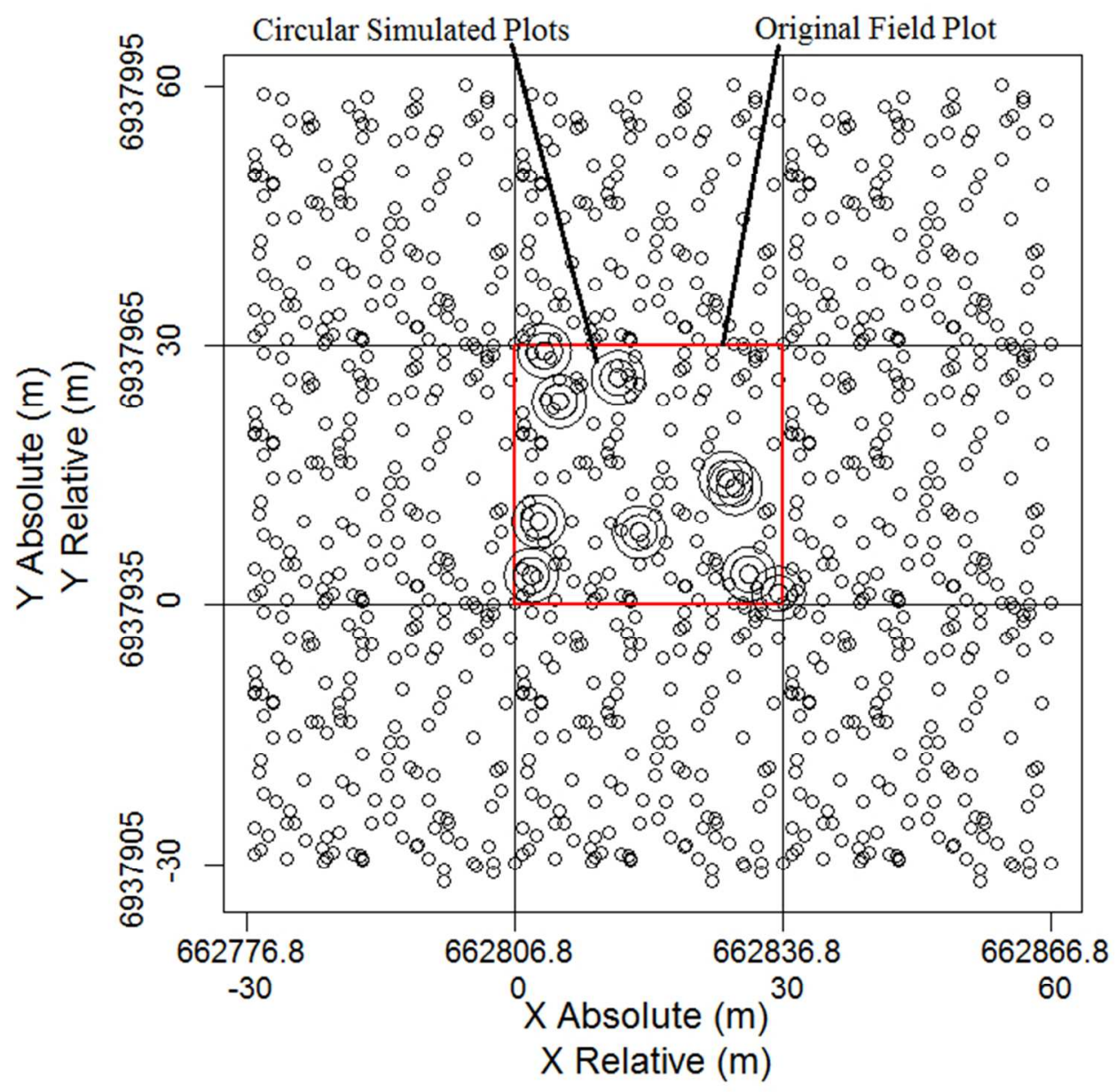

Figure 1

$158 \times 158 \mathrm{~mm}(120 \times 120 \mathrm{DPI})$ 


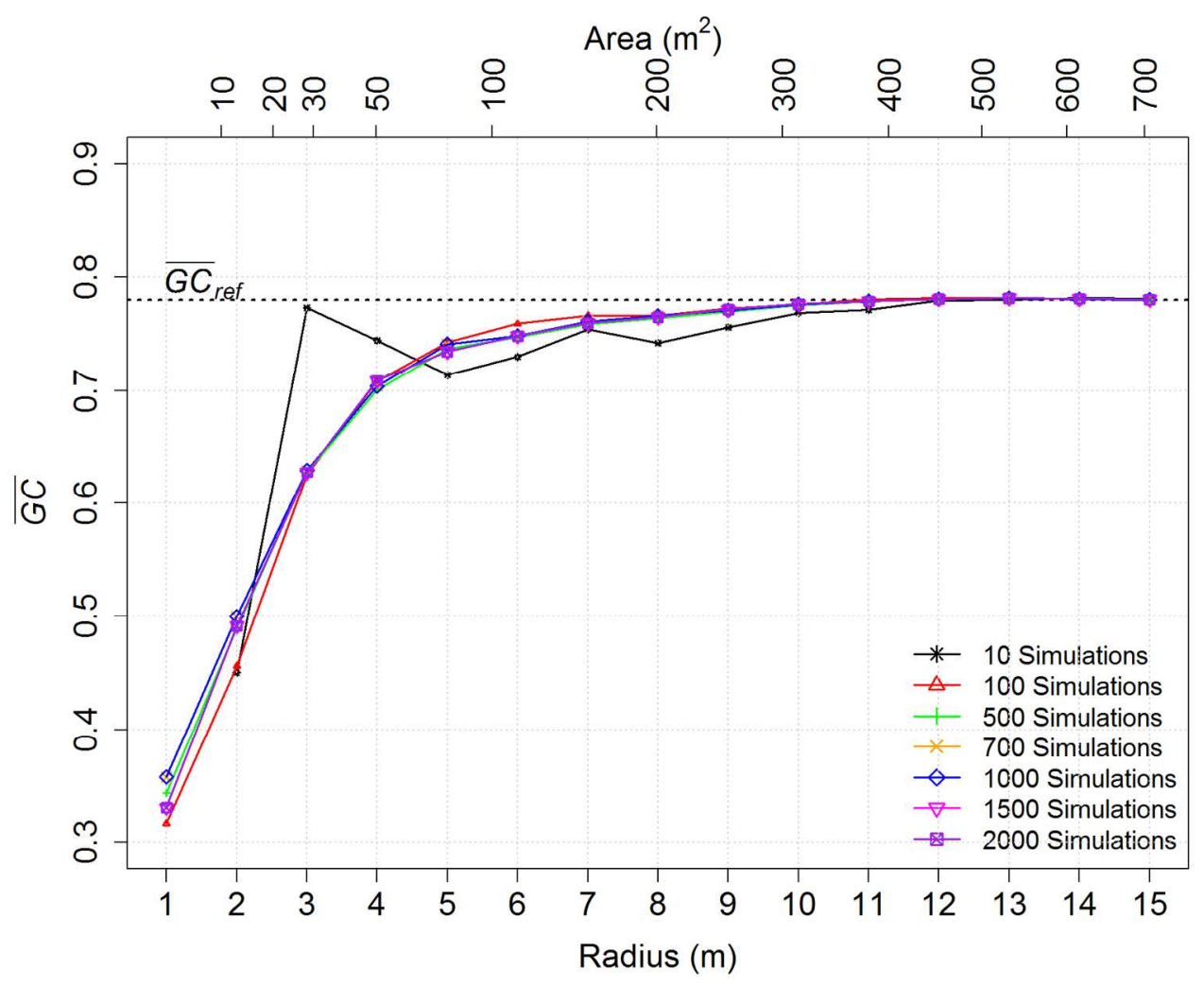

Figure 2(a)

$241 \times 190 \mathrm{~mm}(200 \times 200$ DPI $)$ 


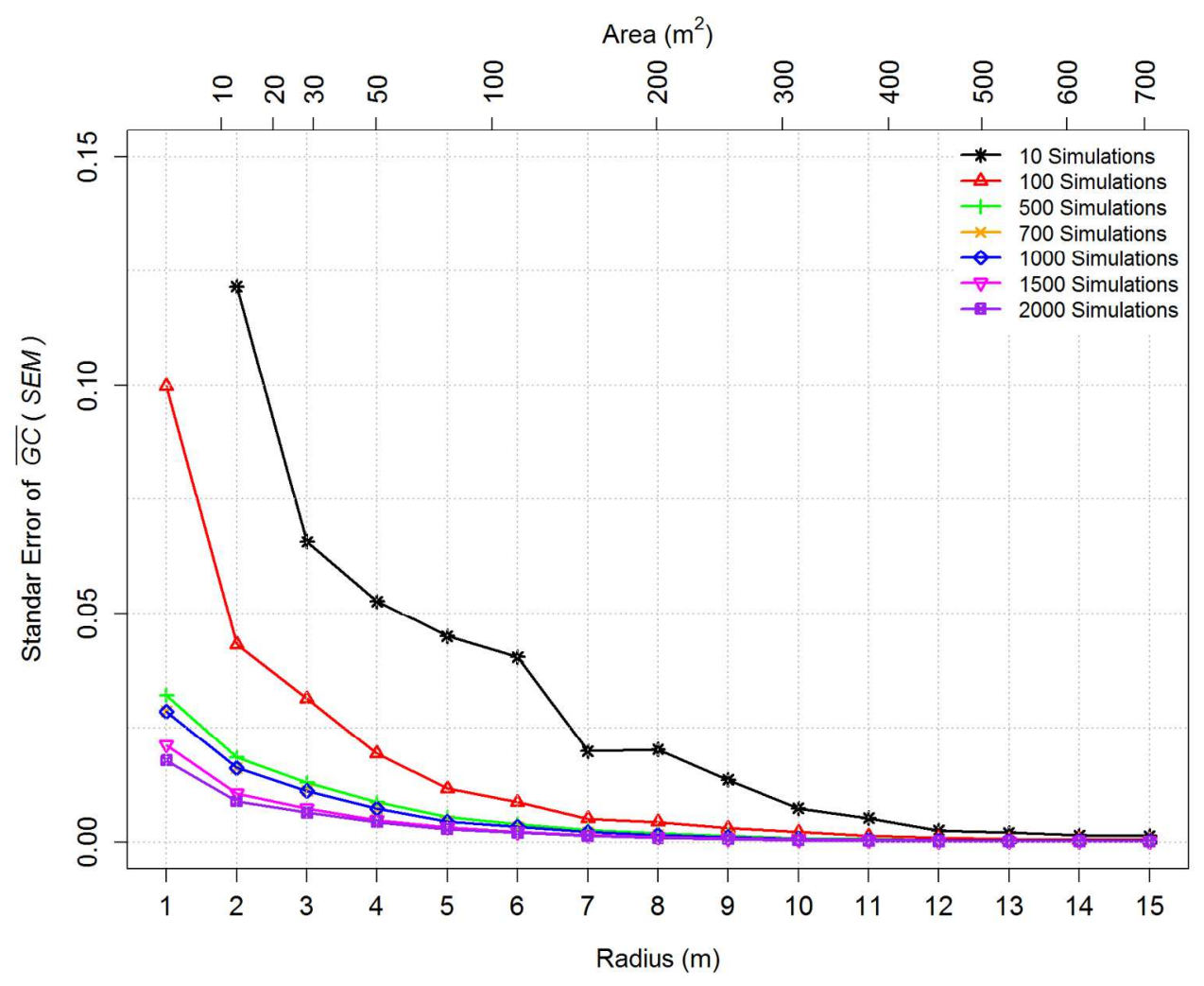

Figure 2(b)

$241 \times 190 \mathrm{~mm}(200 \times 200$ DPI $)$ 


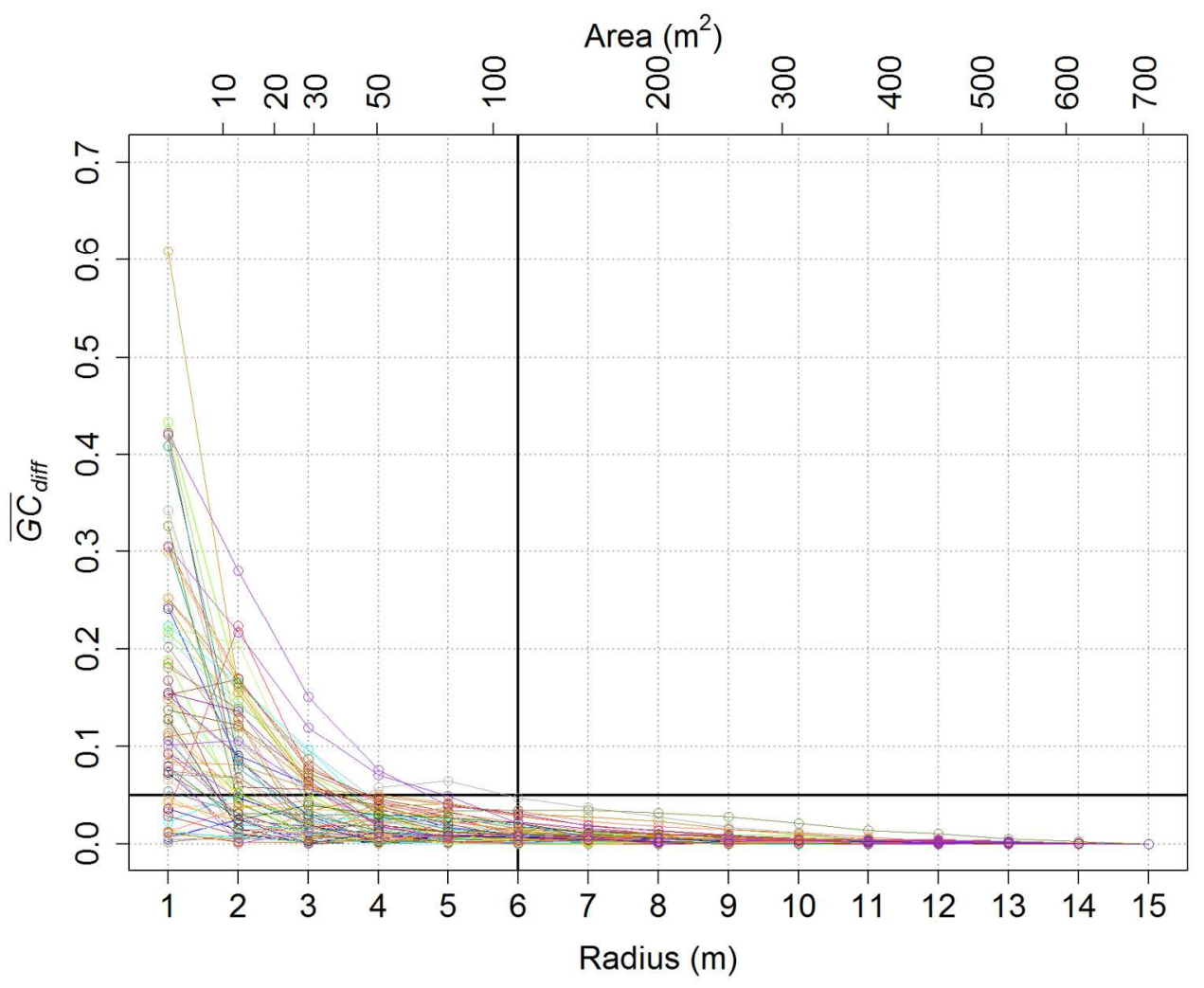

Figure 3(a)

$241 \times 190 \mathrm{~mm}(200 \times 200$ DPI $)$ 


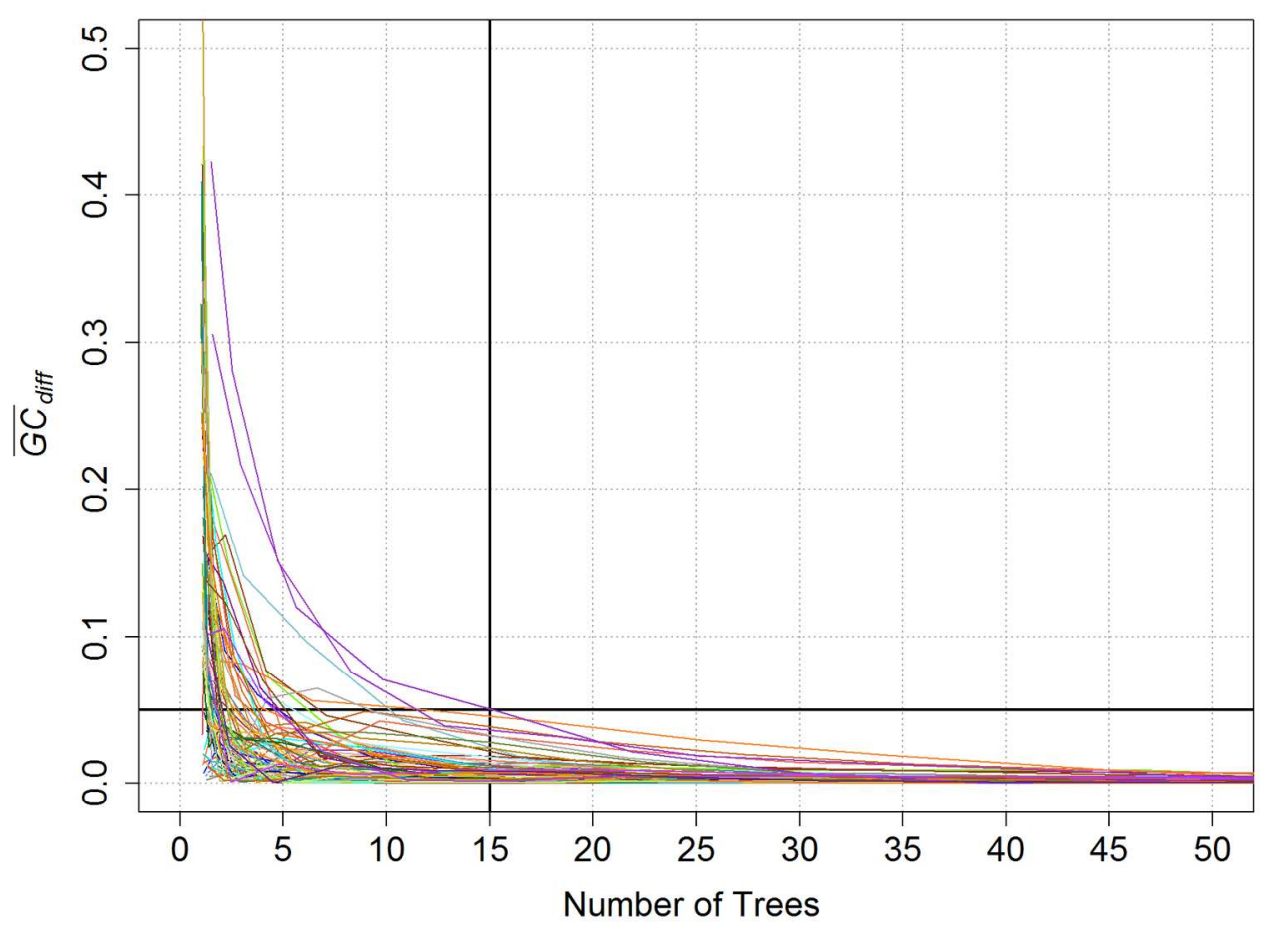

Figure 3(b)

$241 \times 190 \mathrm{~mm}(200 \times 200$ DPI $)$ 


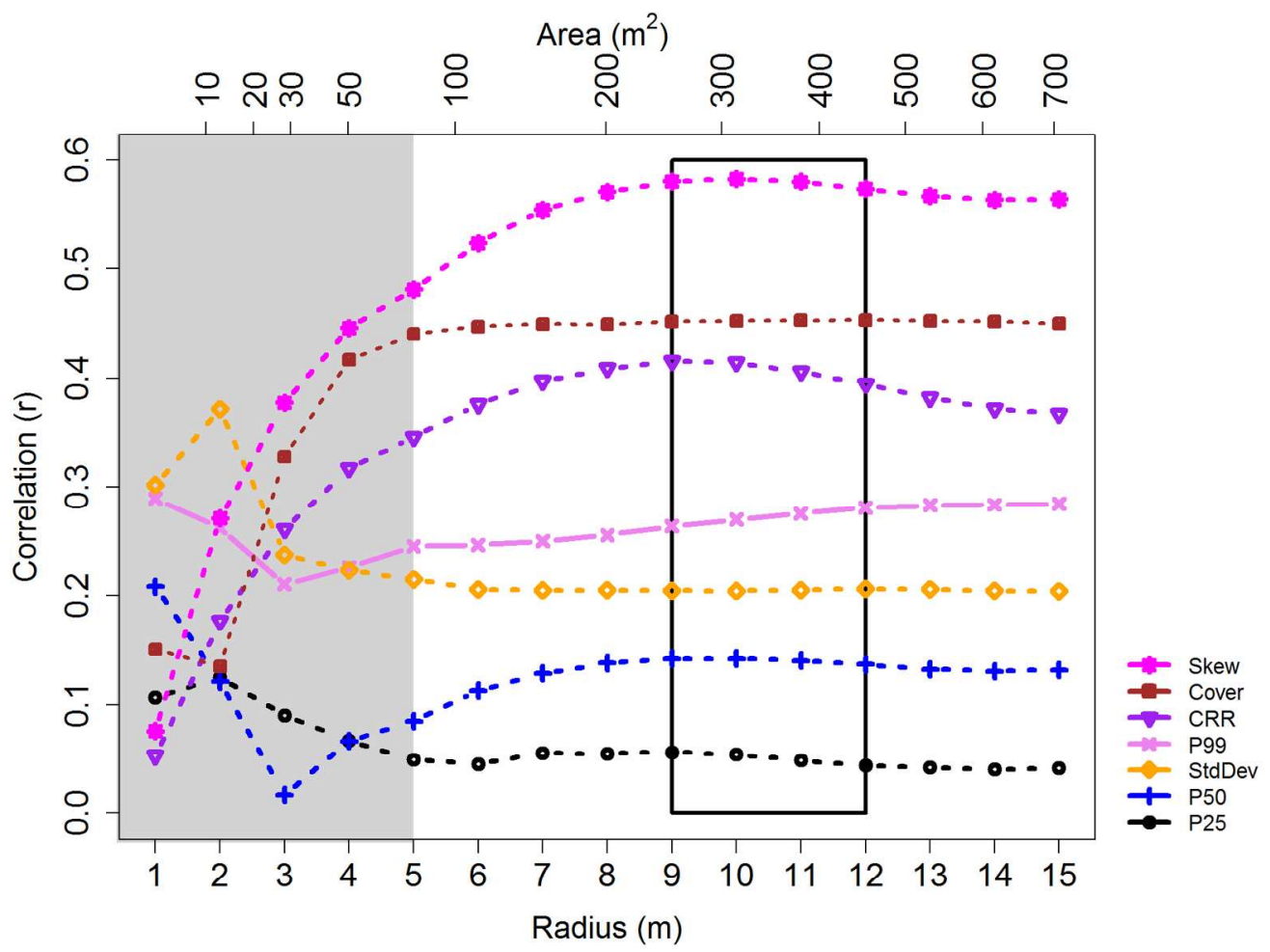

Figure $4(a)$

$241 \times 190 \mathrm{~mm}(200 \times 200$ DPI $)$ 


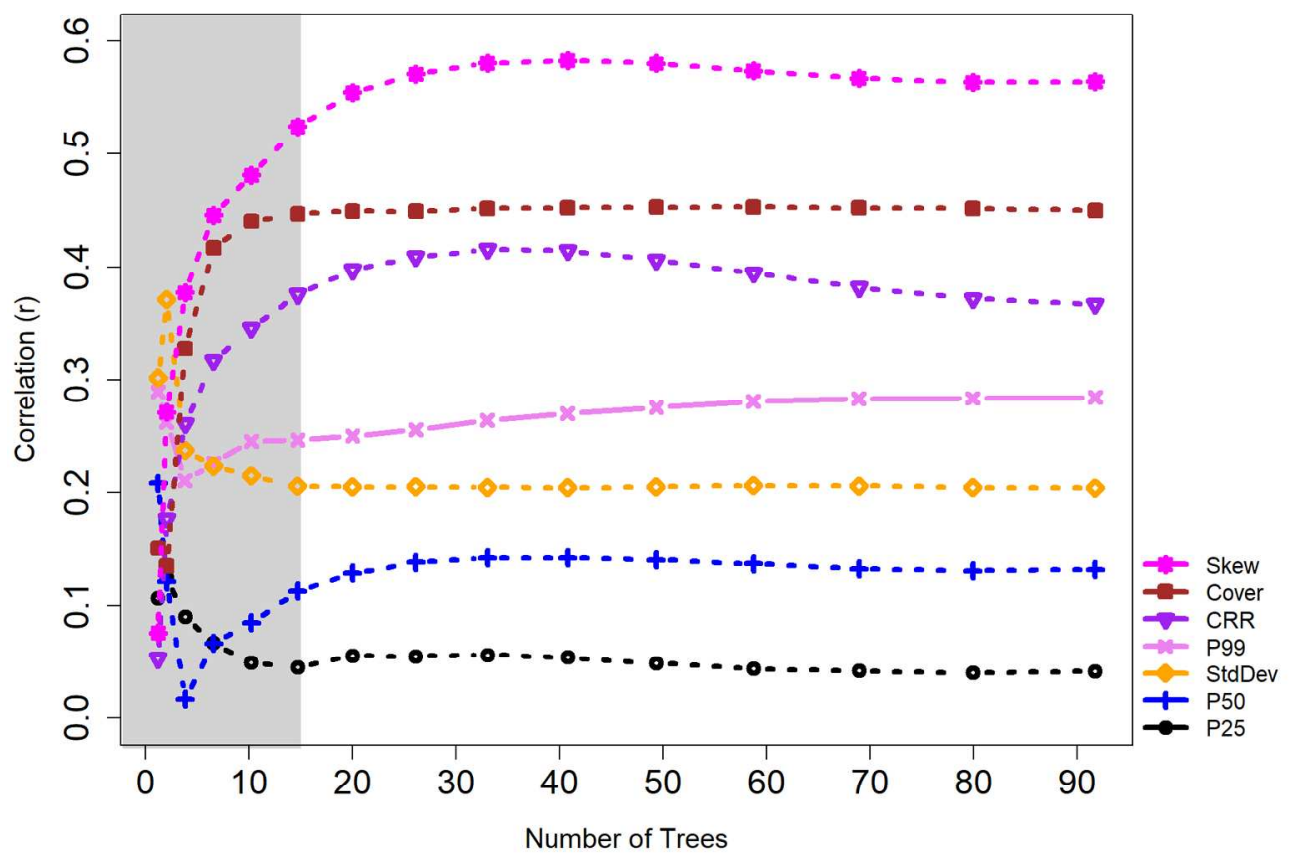

Figure 4(b)

$241 \times 190 \mathrm{~mm}(200 \times 200$ DPI $)$ 


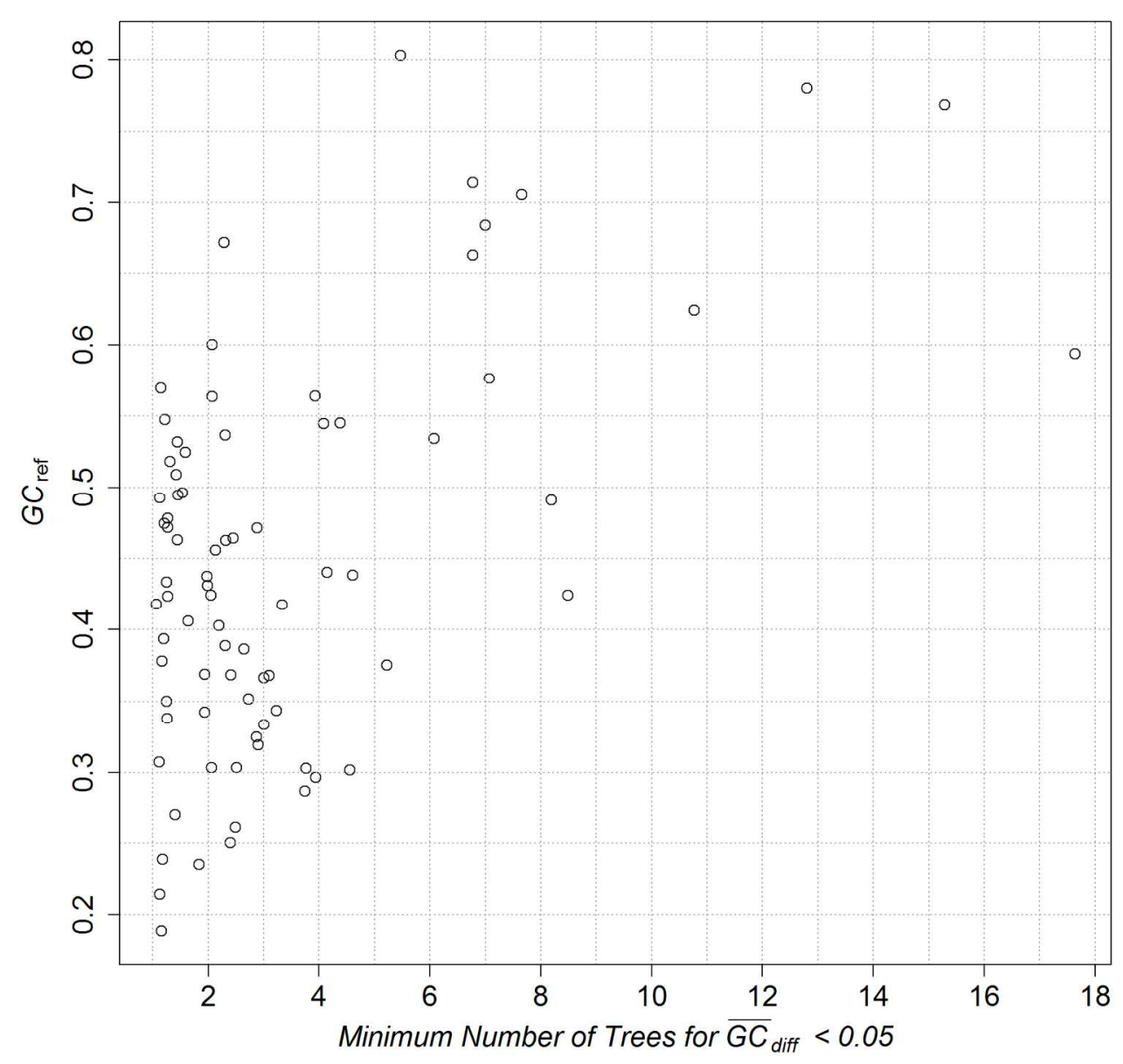

Figure 5

$254 \times 254 \mathrm{~mm}(200 \times 200 \mathrm{DPI})$ 


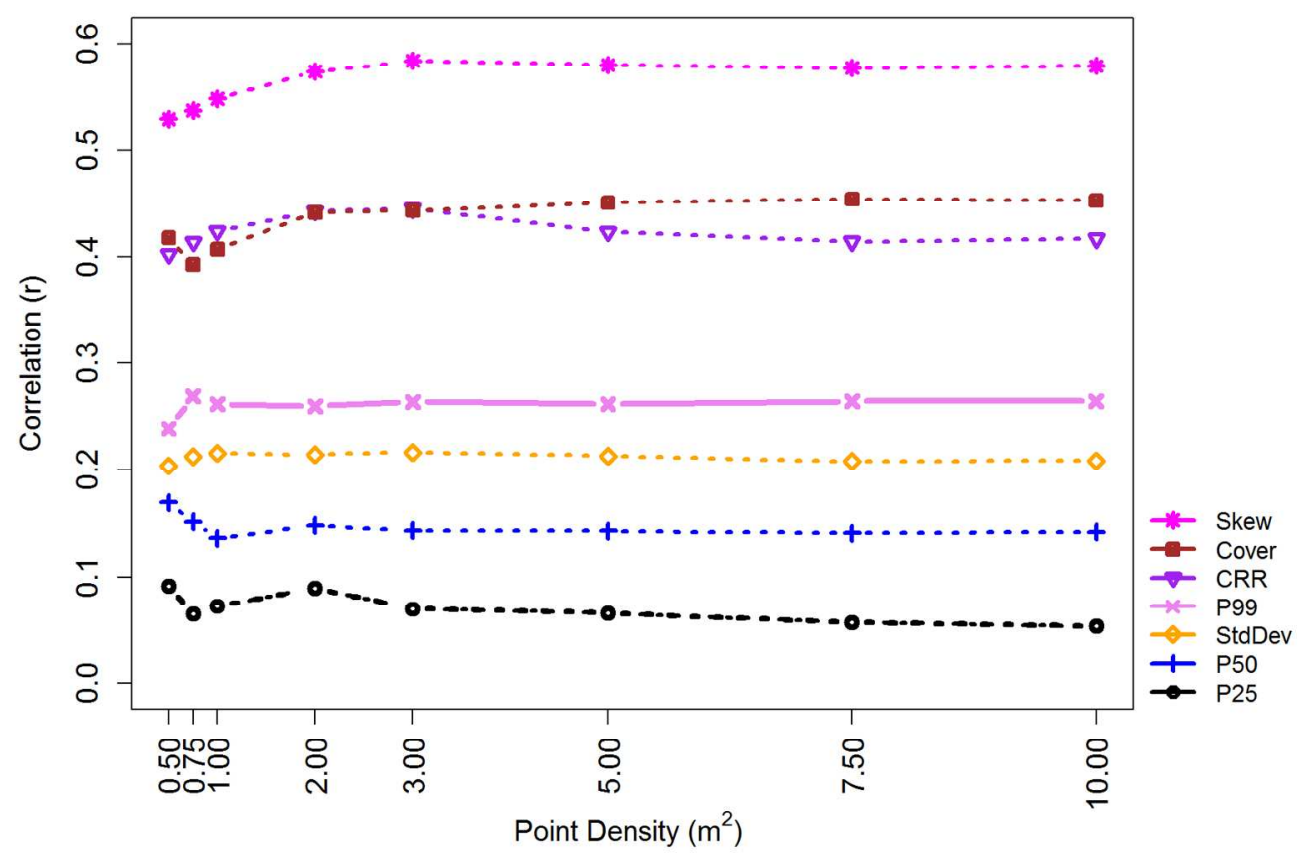

Figure 6

$228 \times 165 \mathrm{~mm}(200 \times 200$ DPI $)$ 

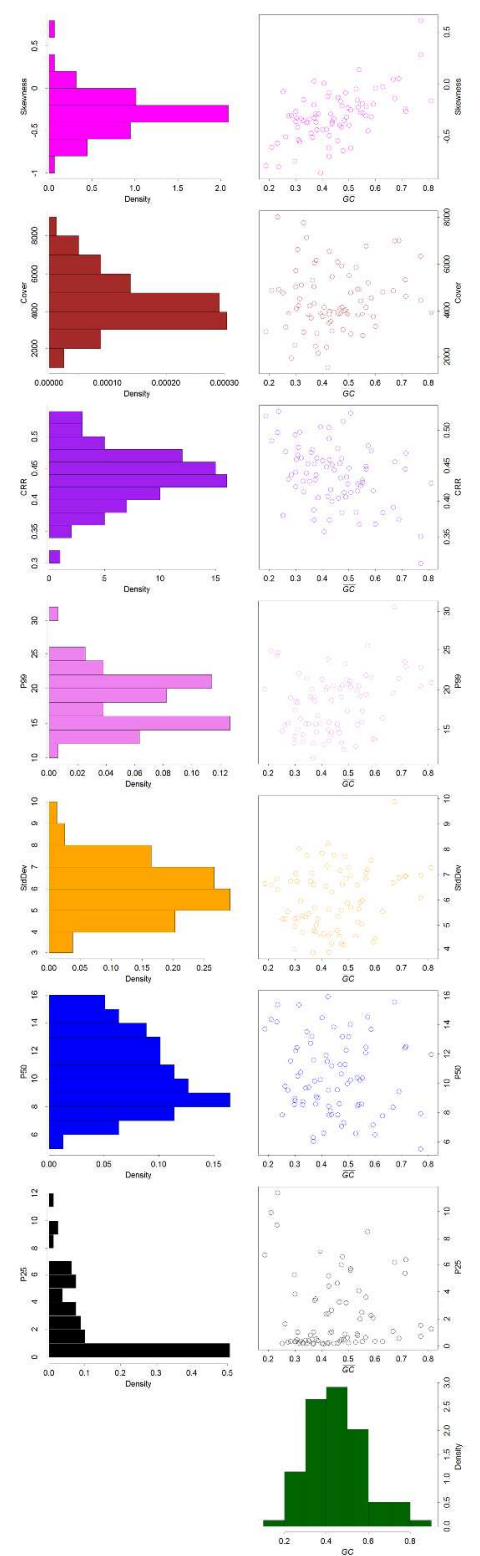

$558 \times 1625 \mathrm{~mm}(100 \times 100 \mathrm{DPI})$ 